
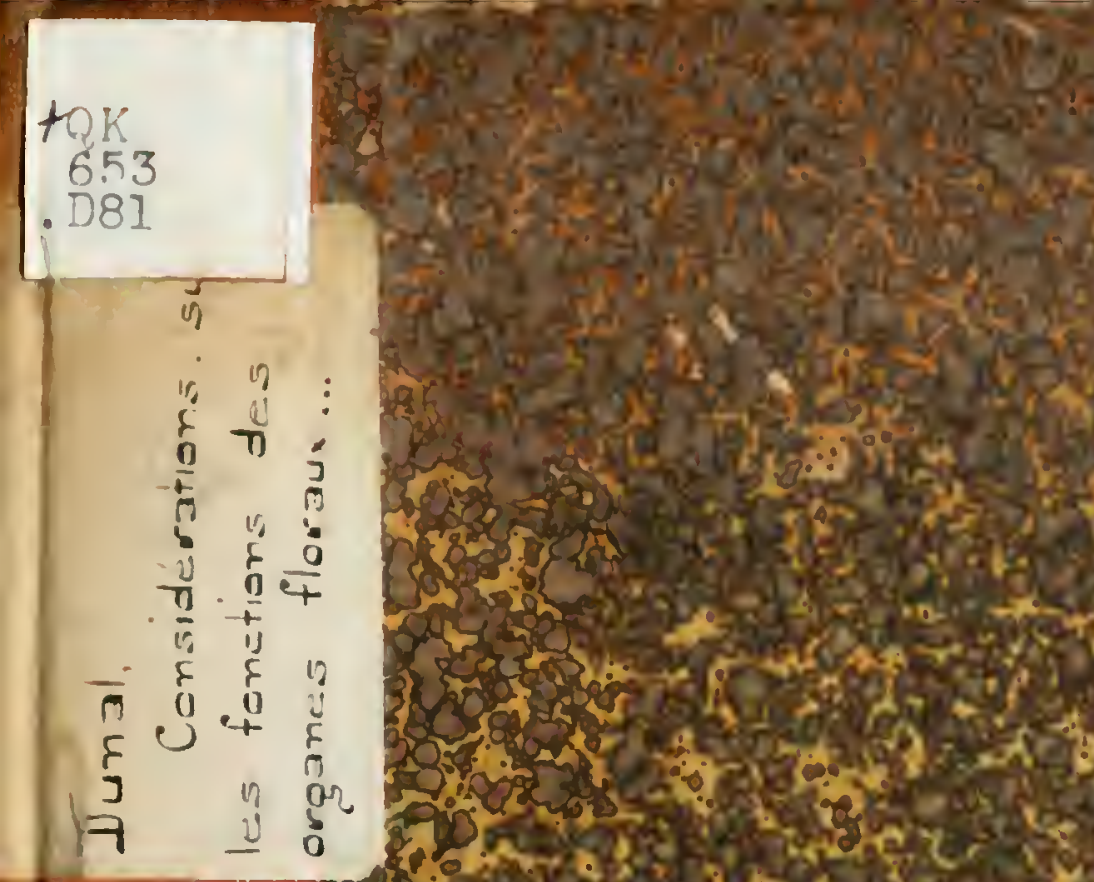

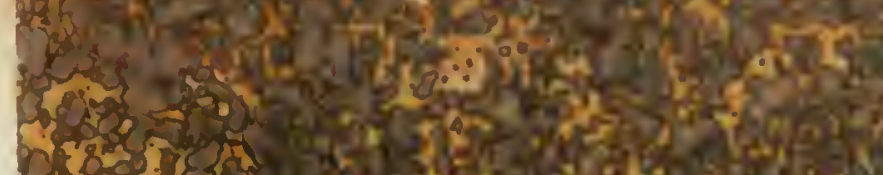

tor.

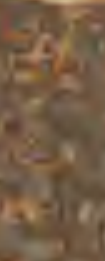

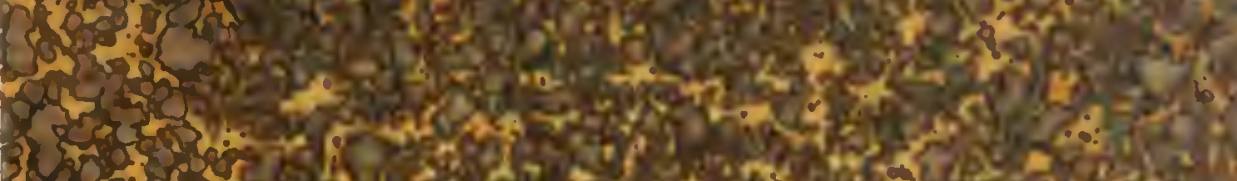

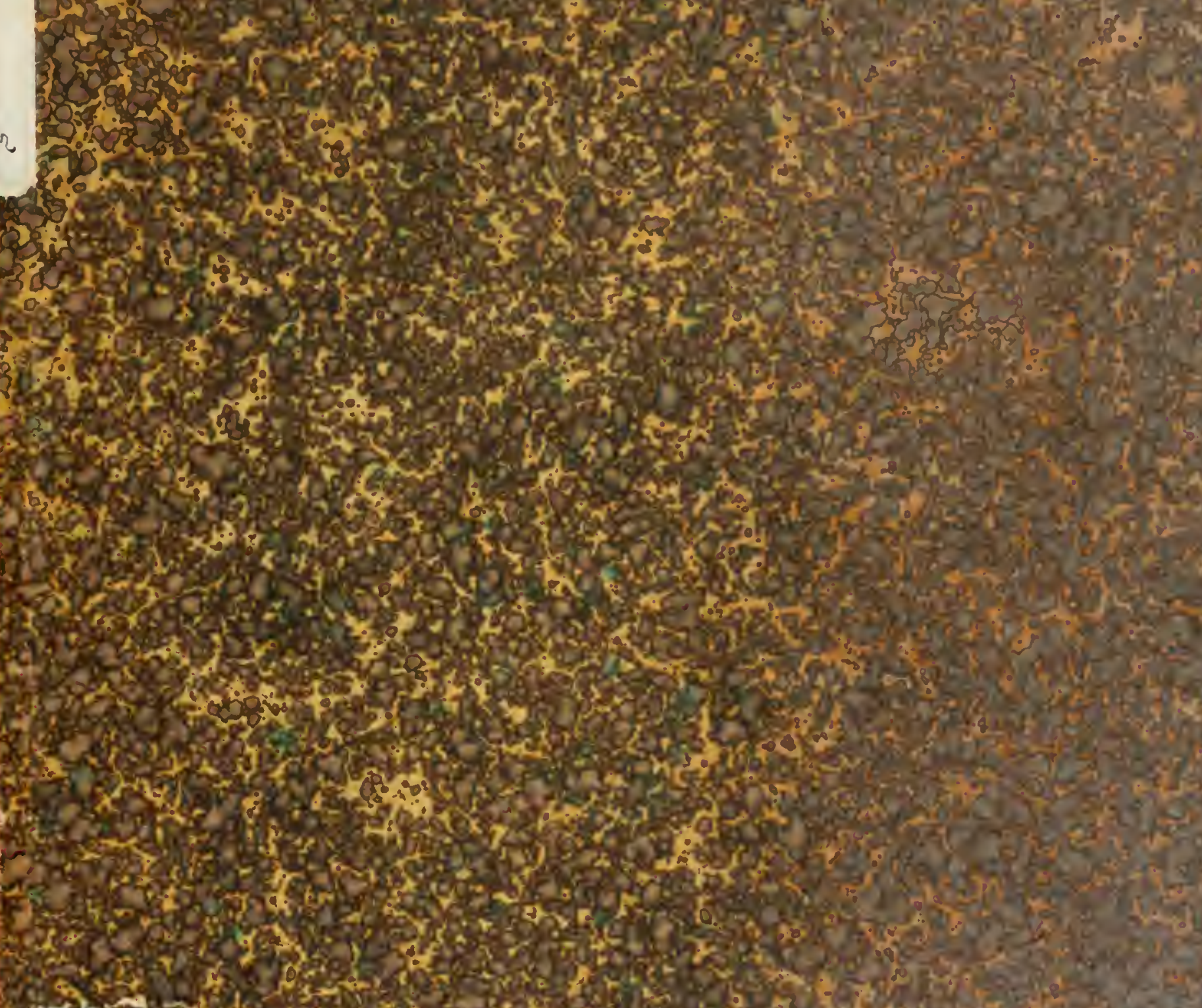

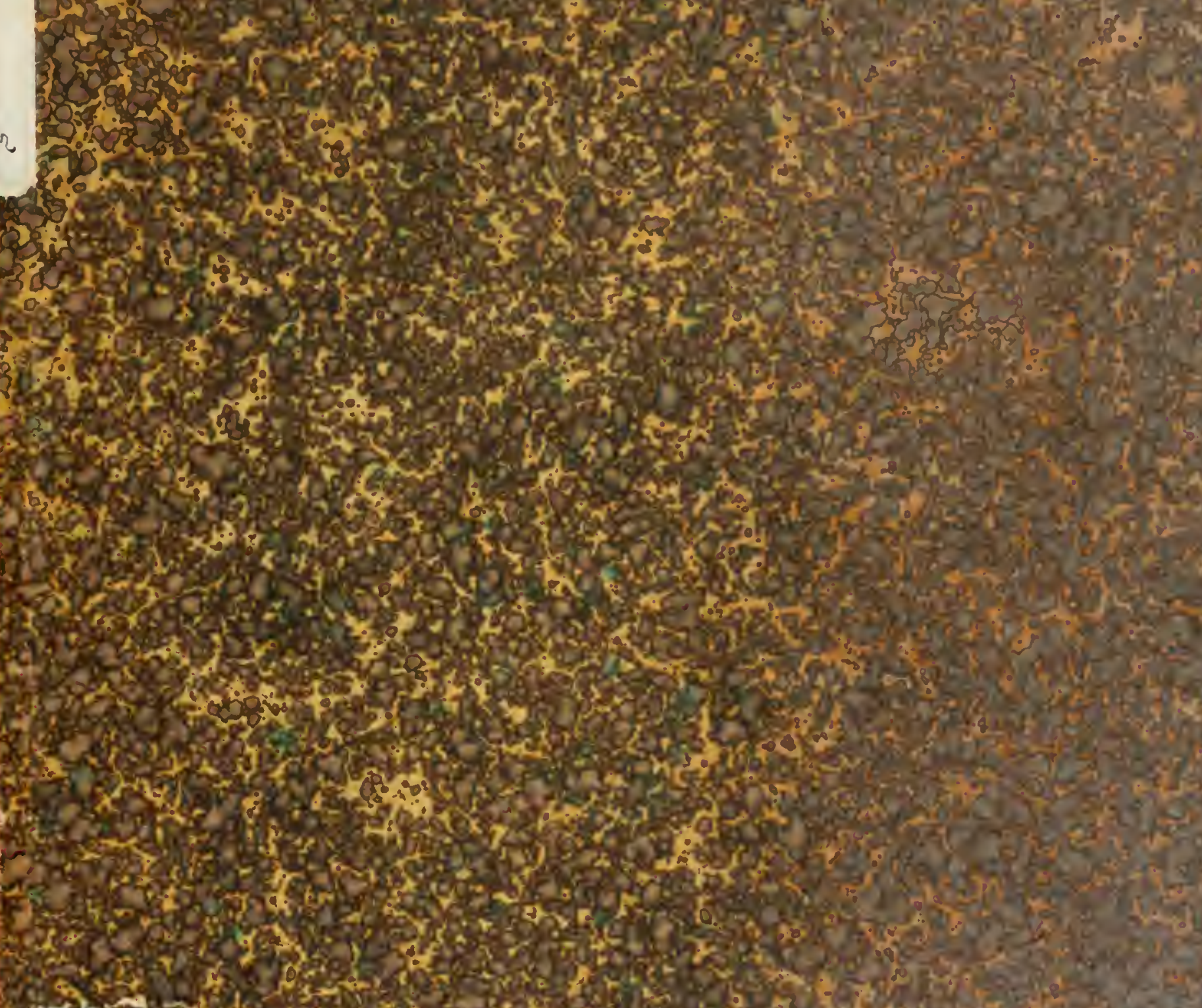

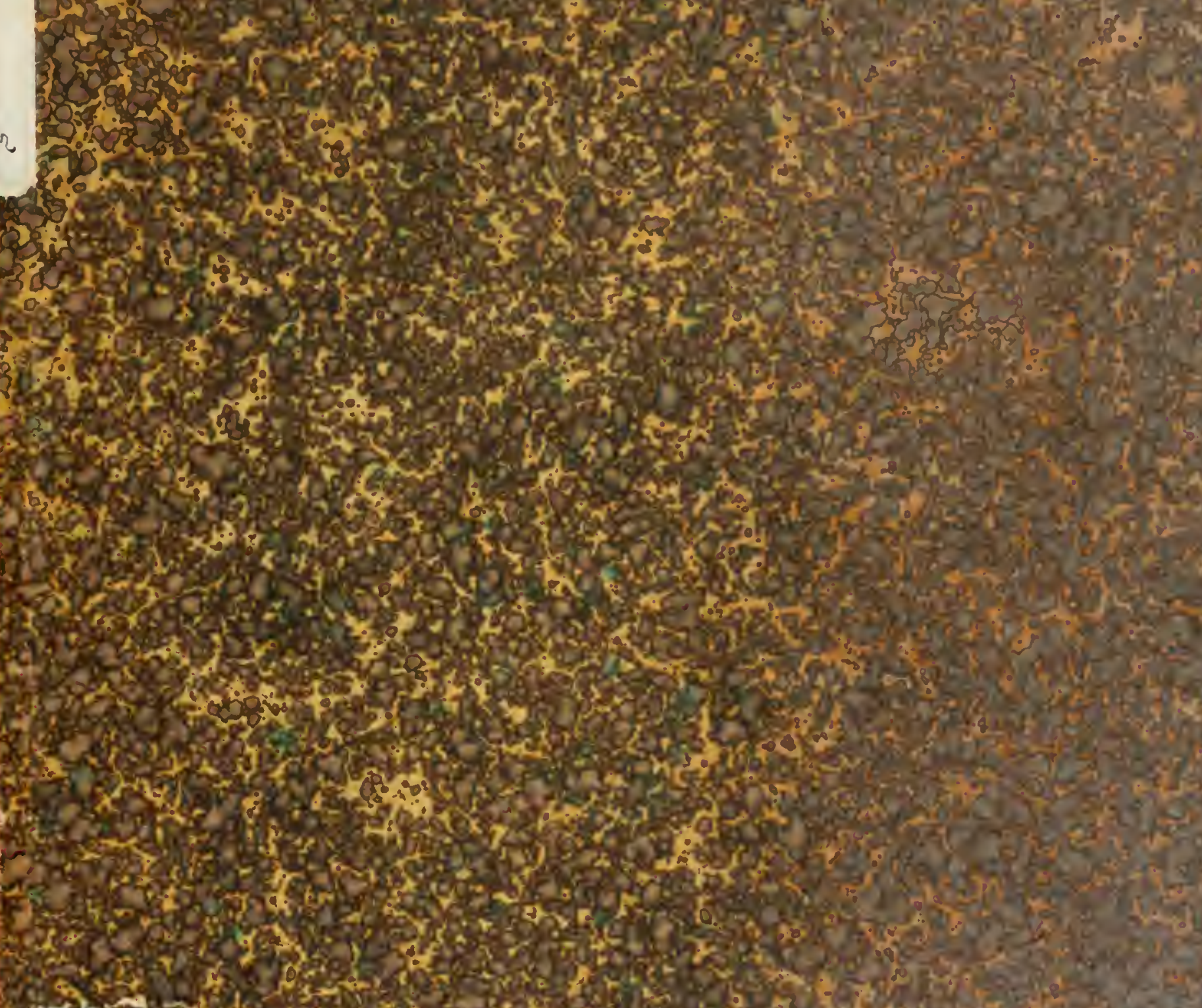

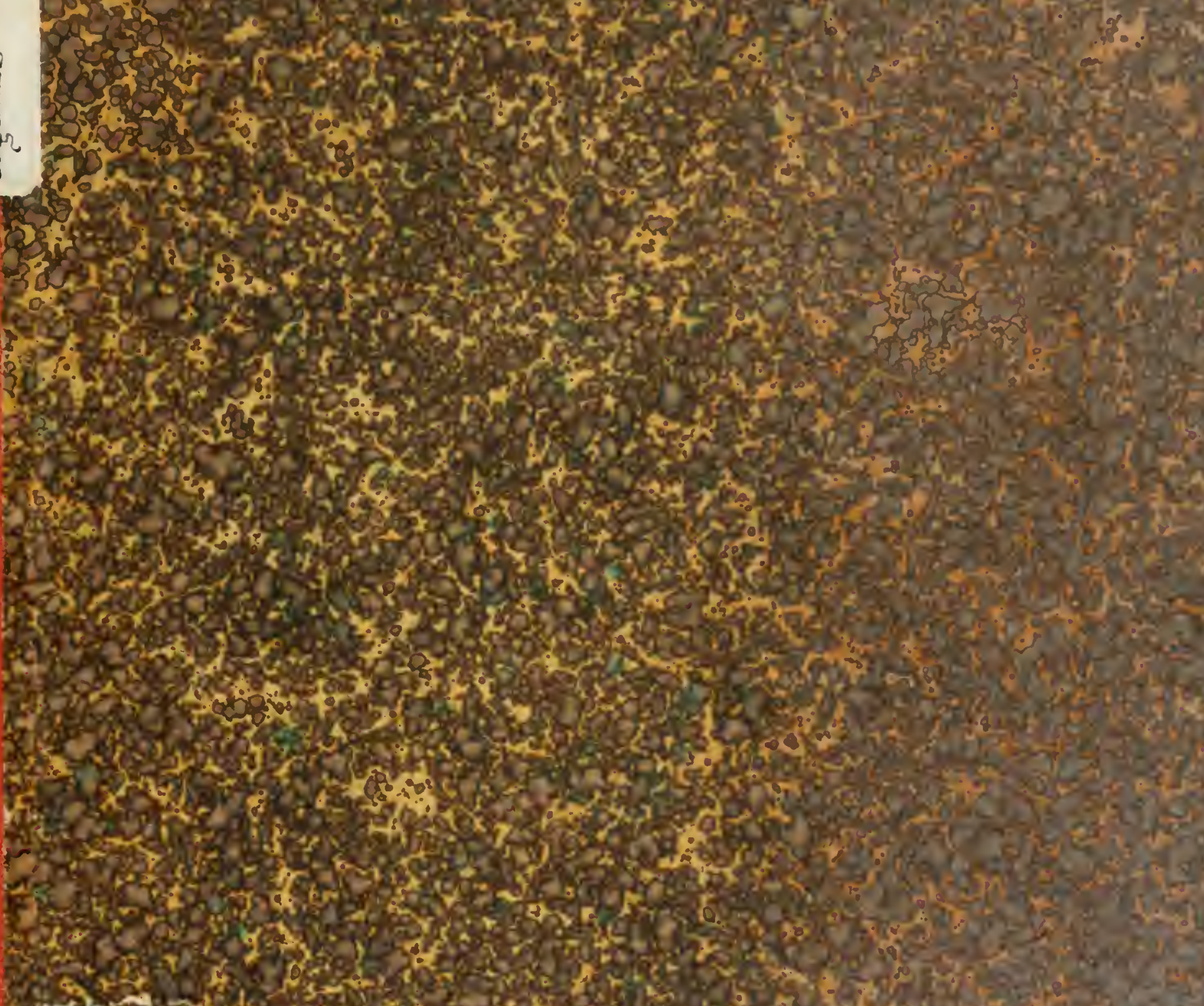

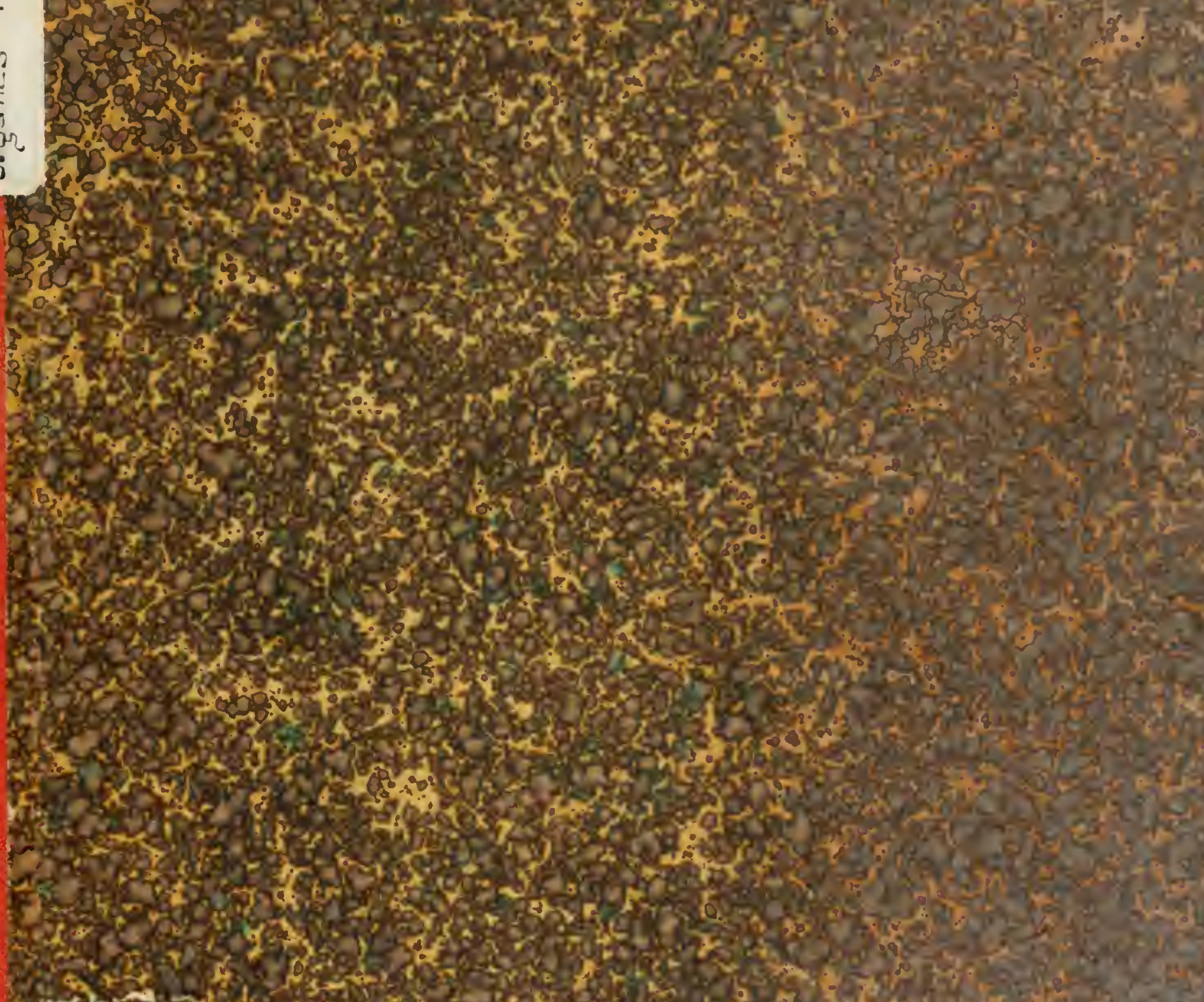

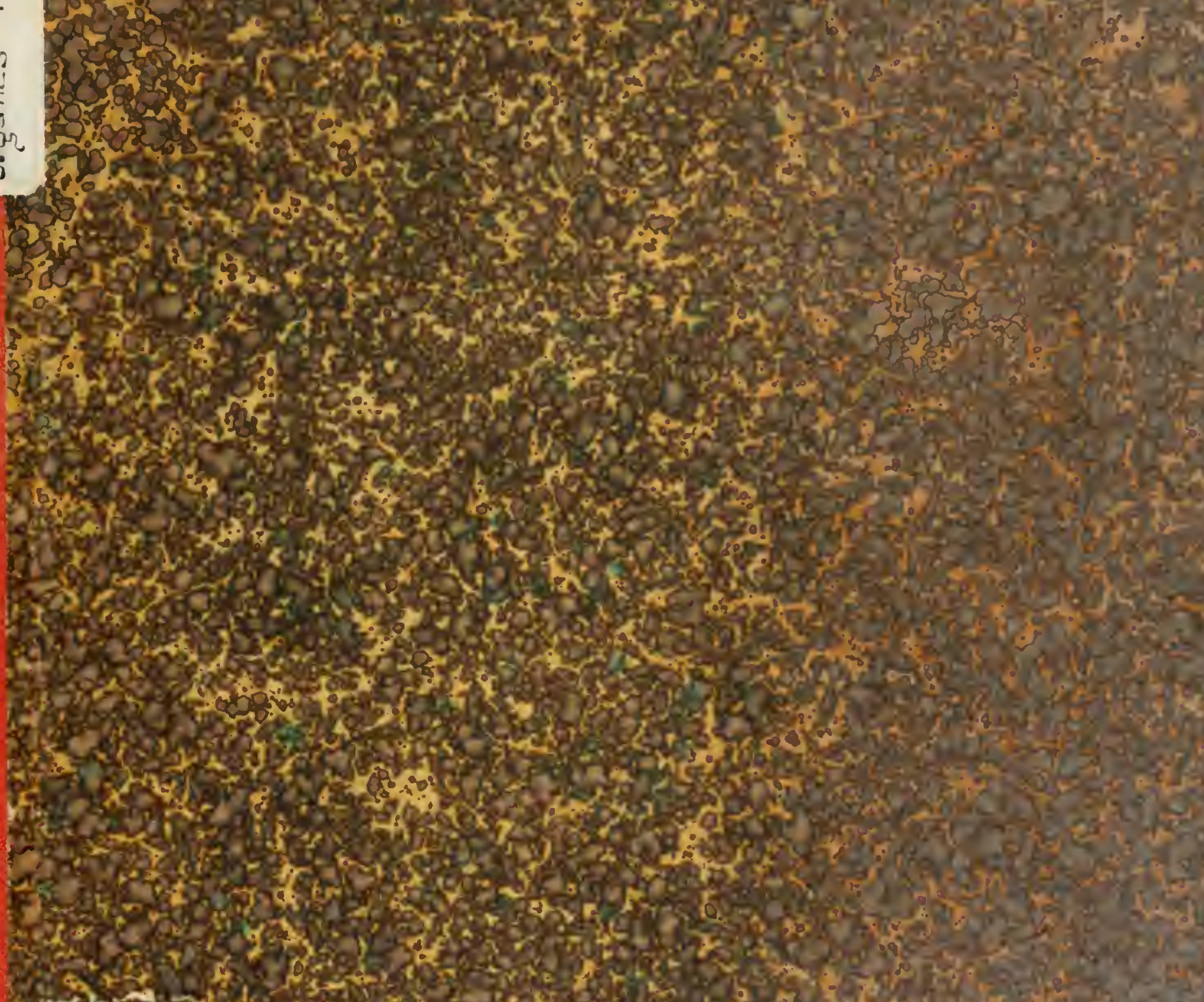

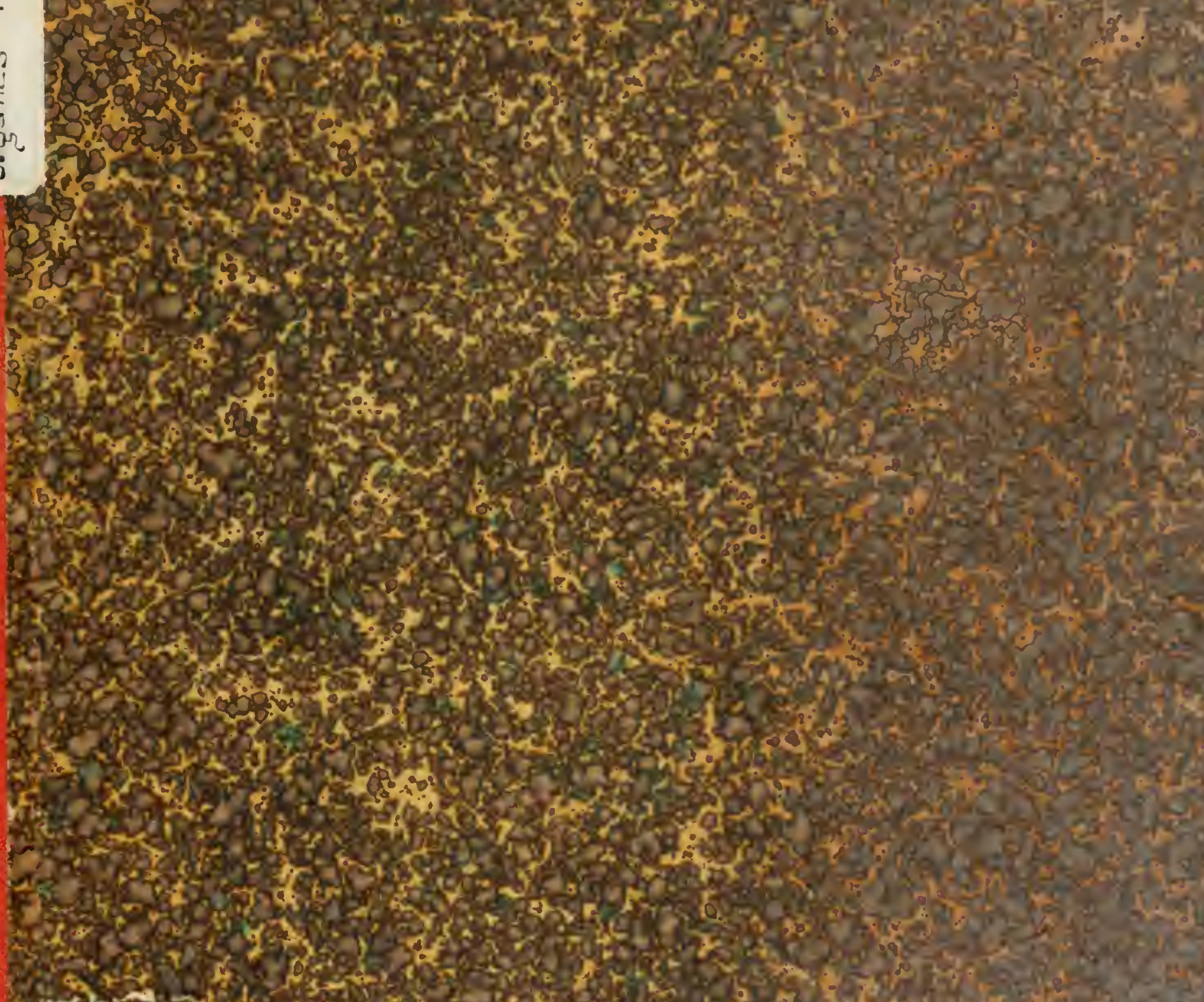

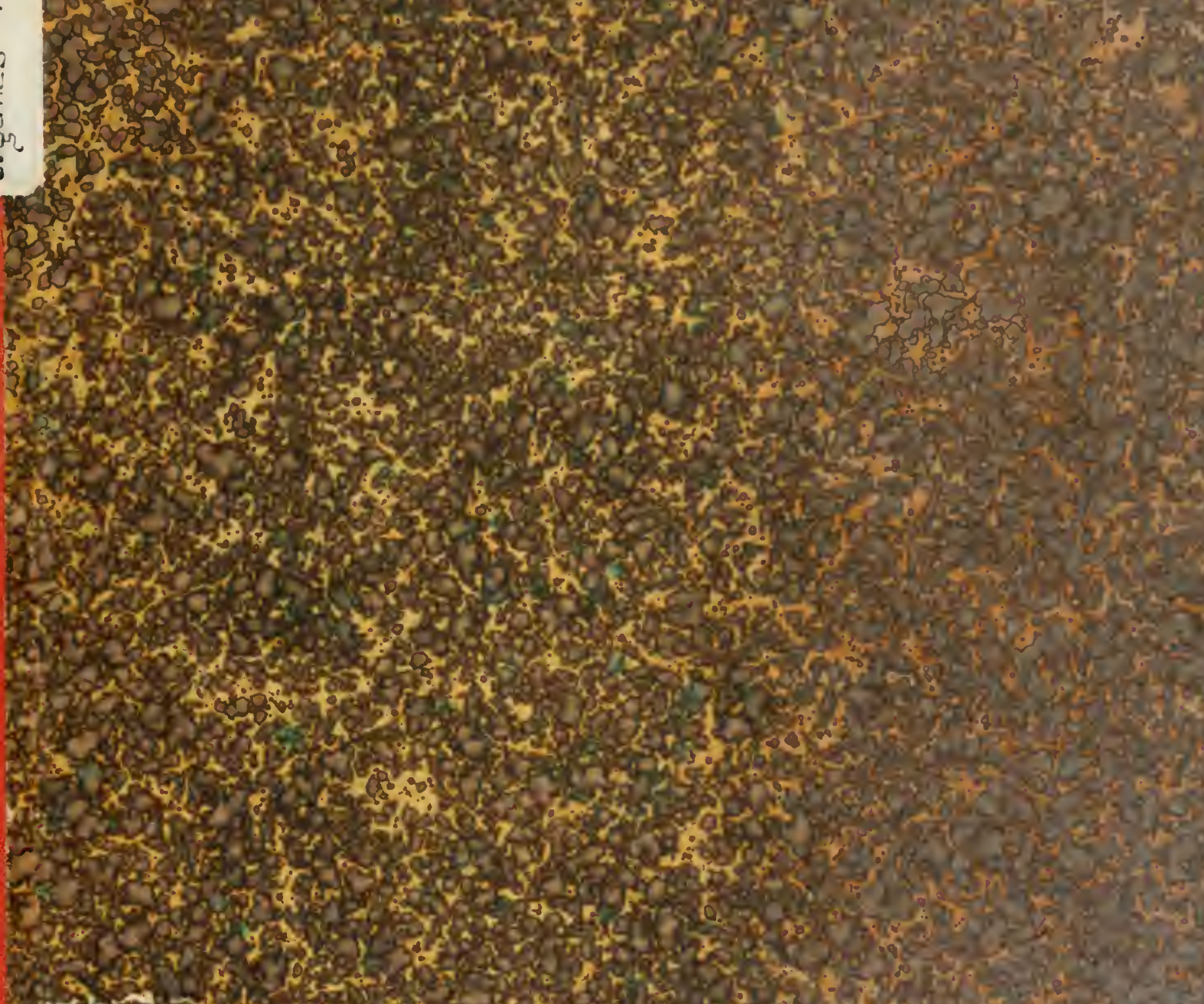

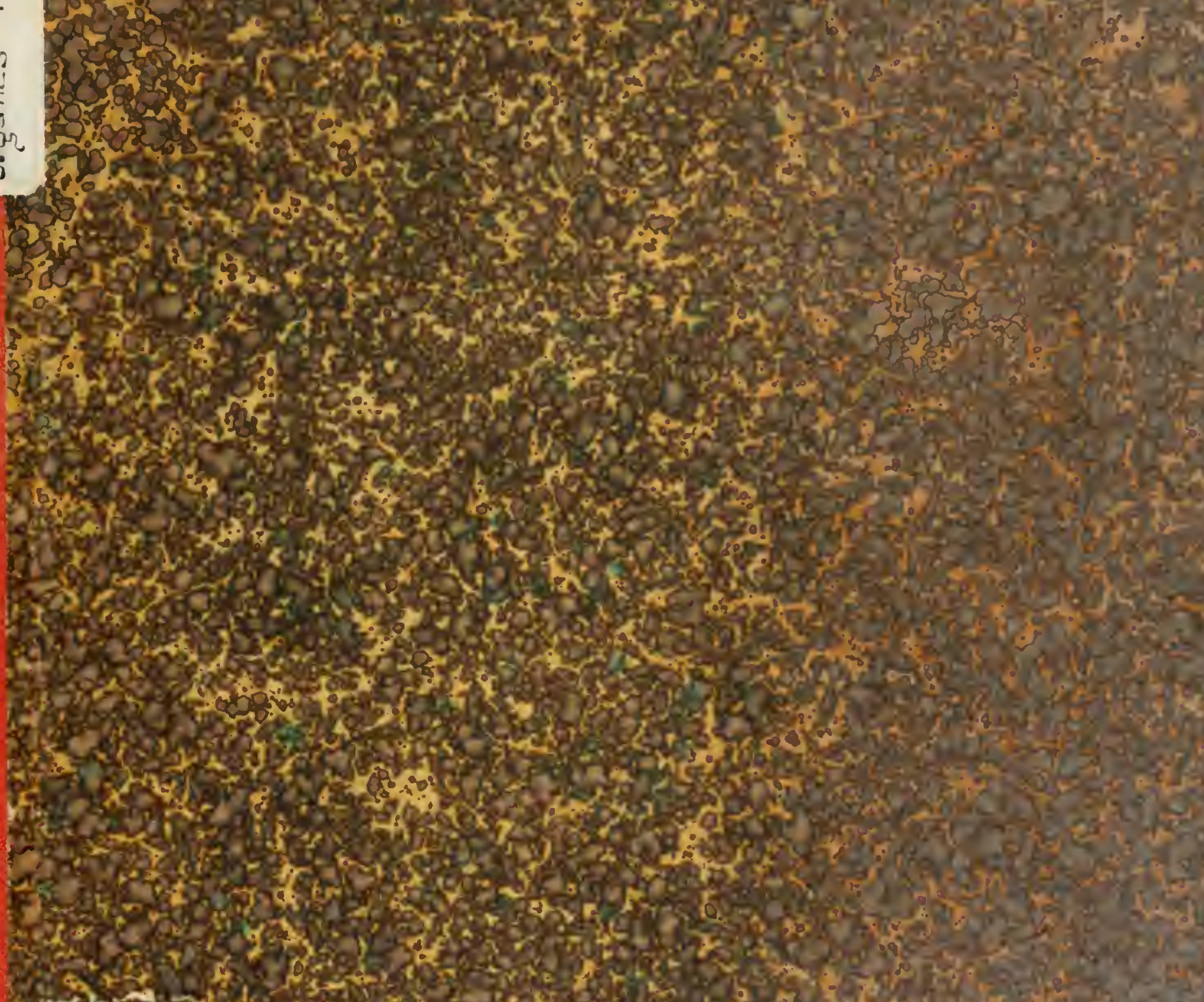

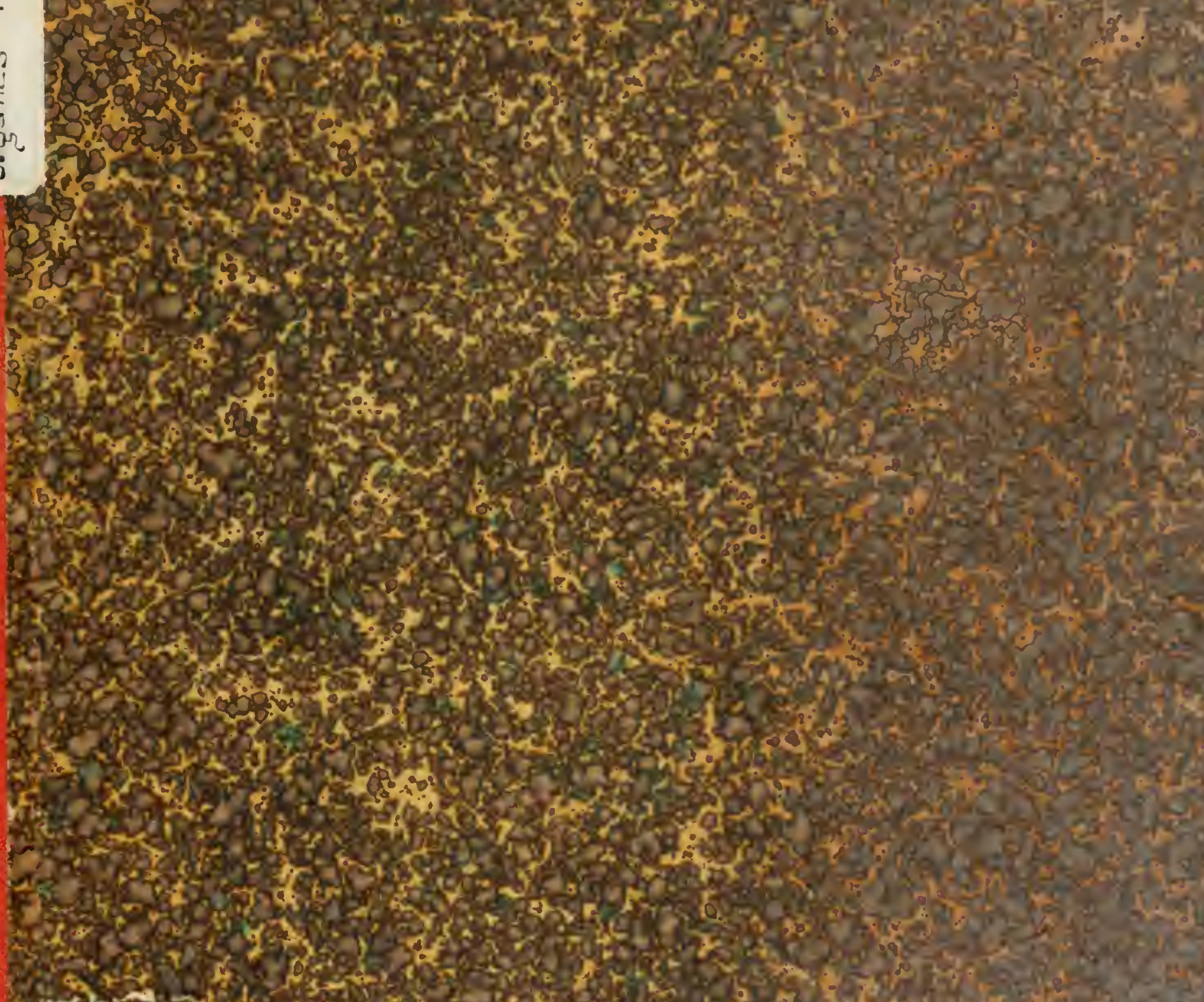

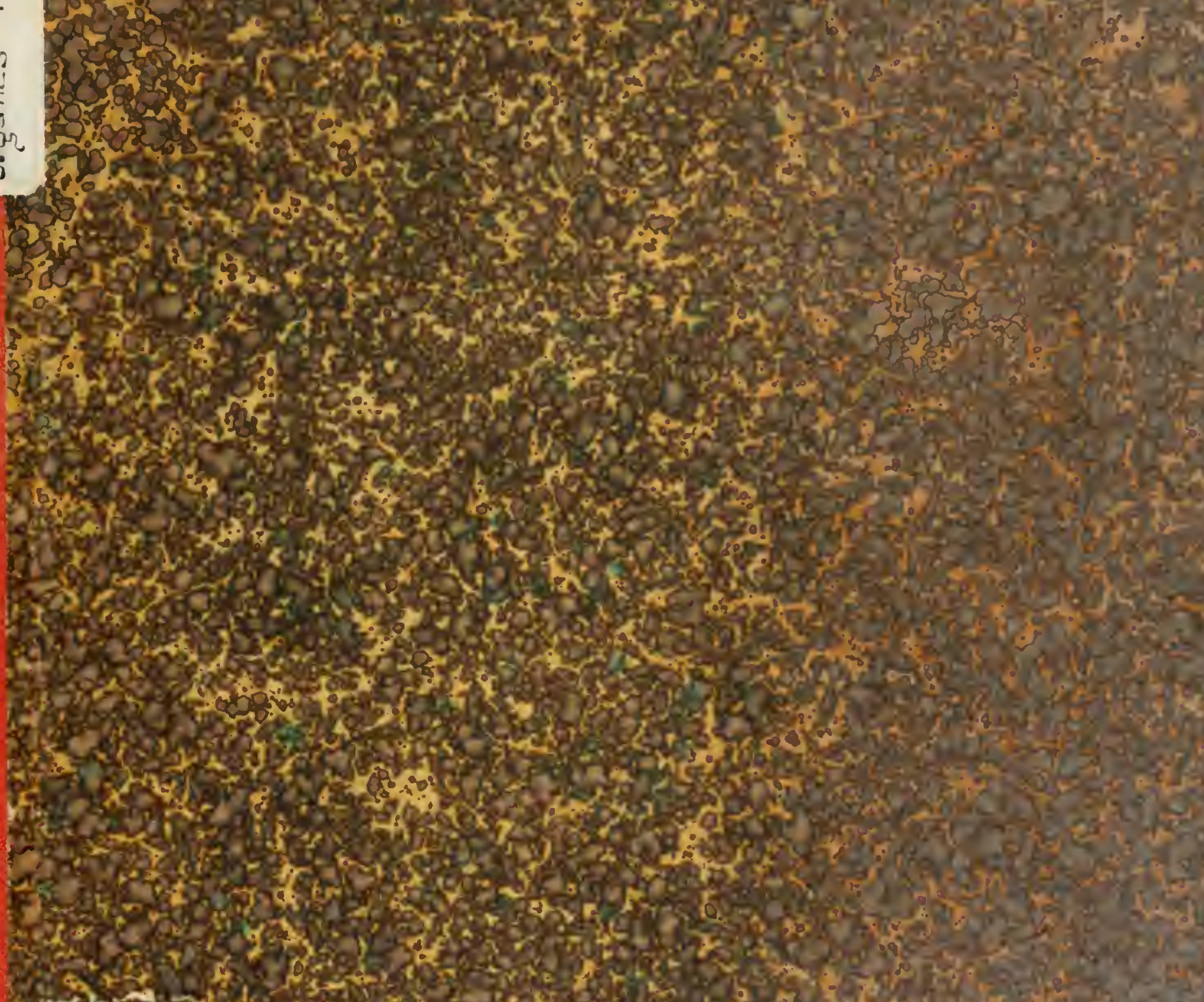

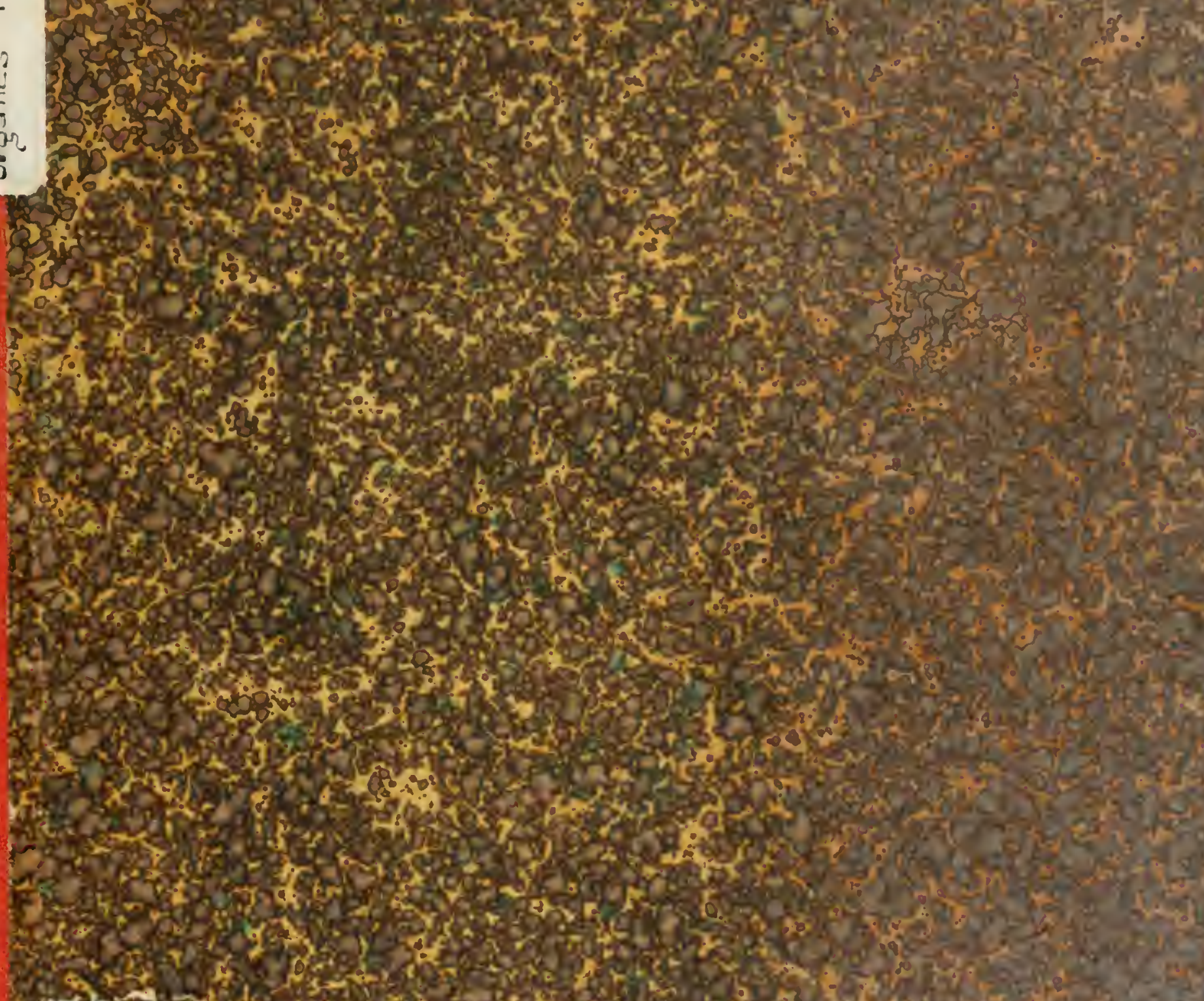

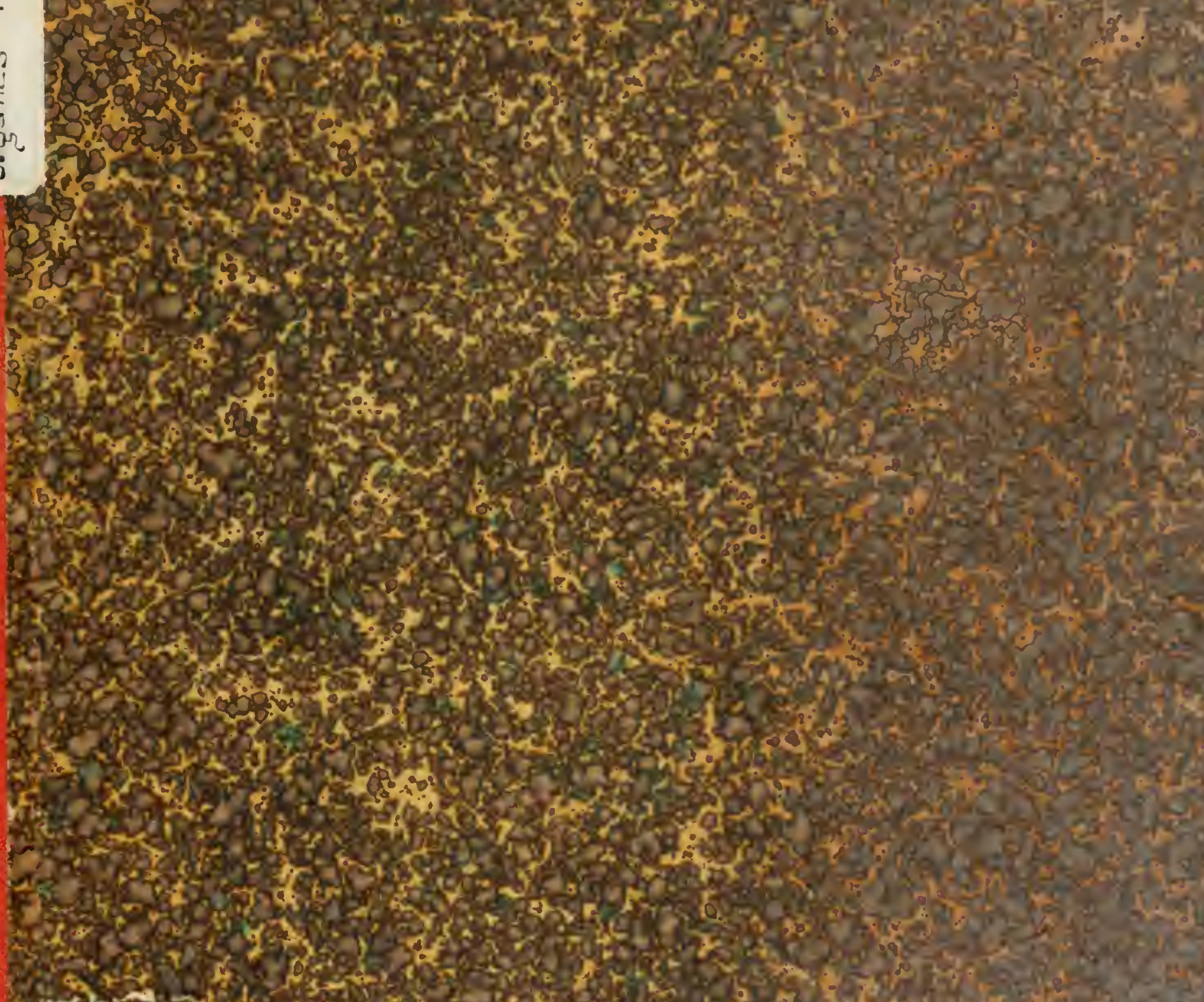

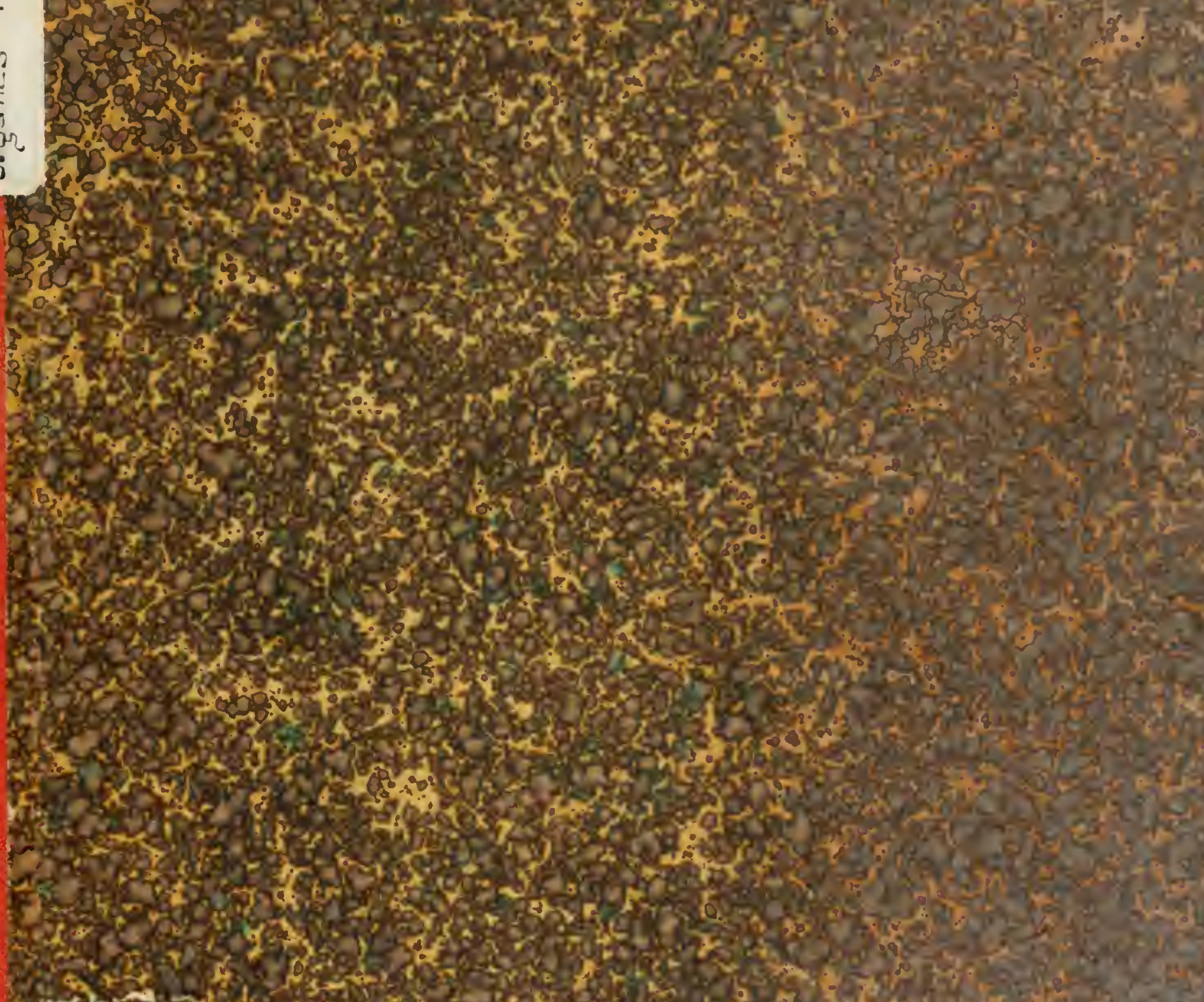

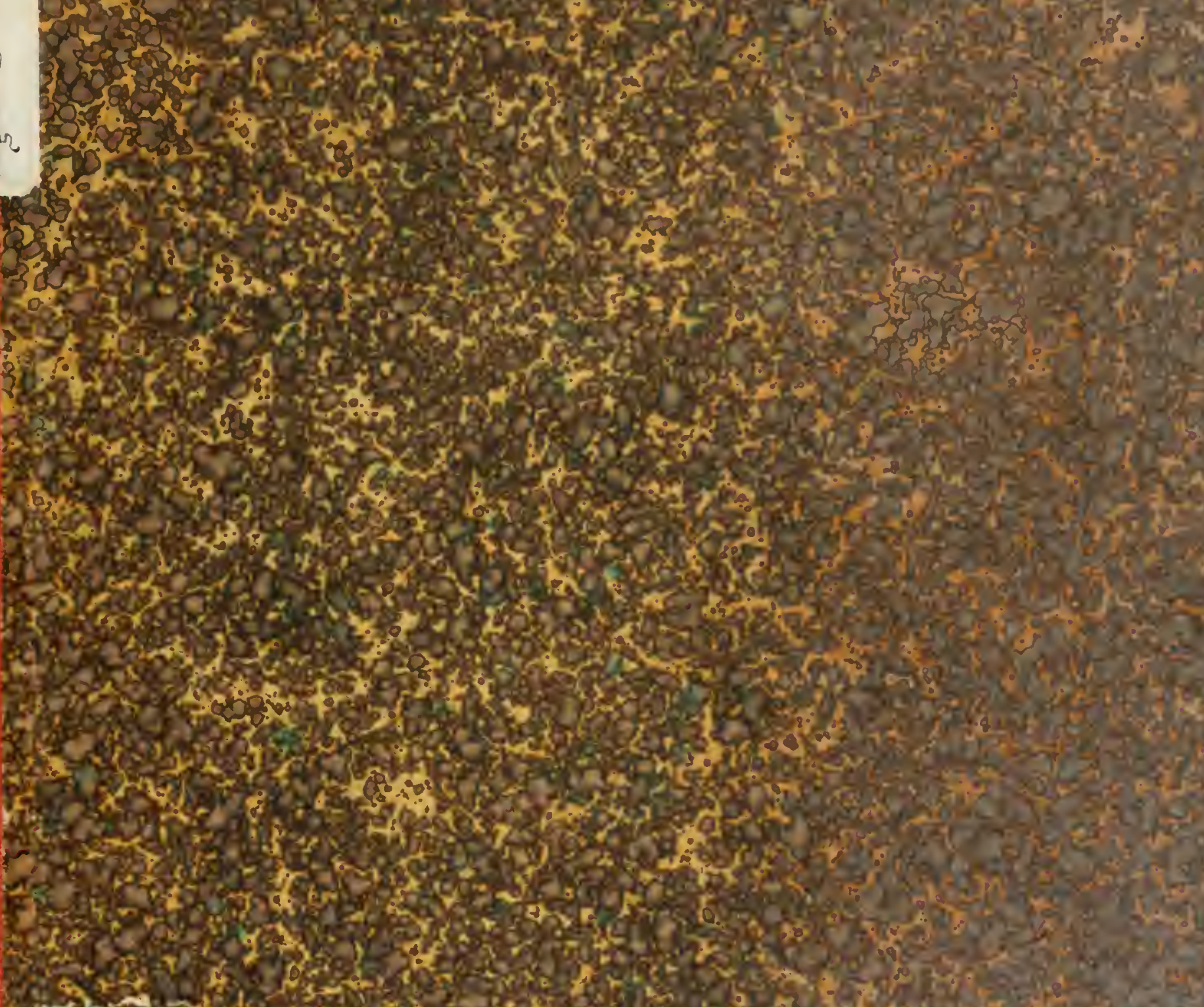

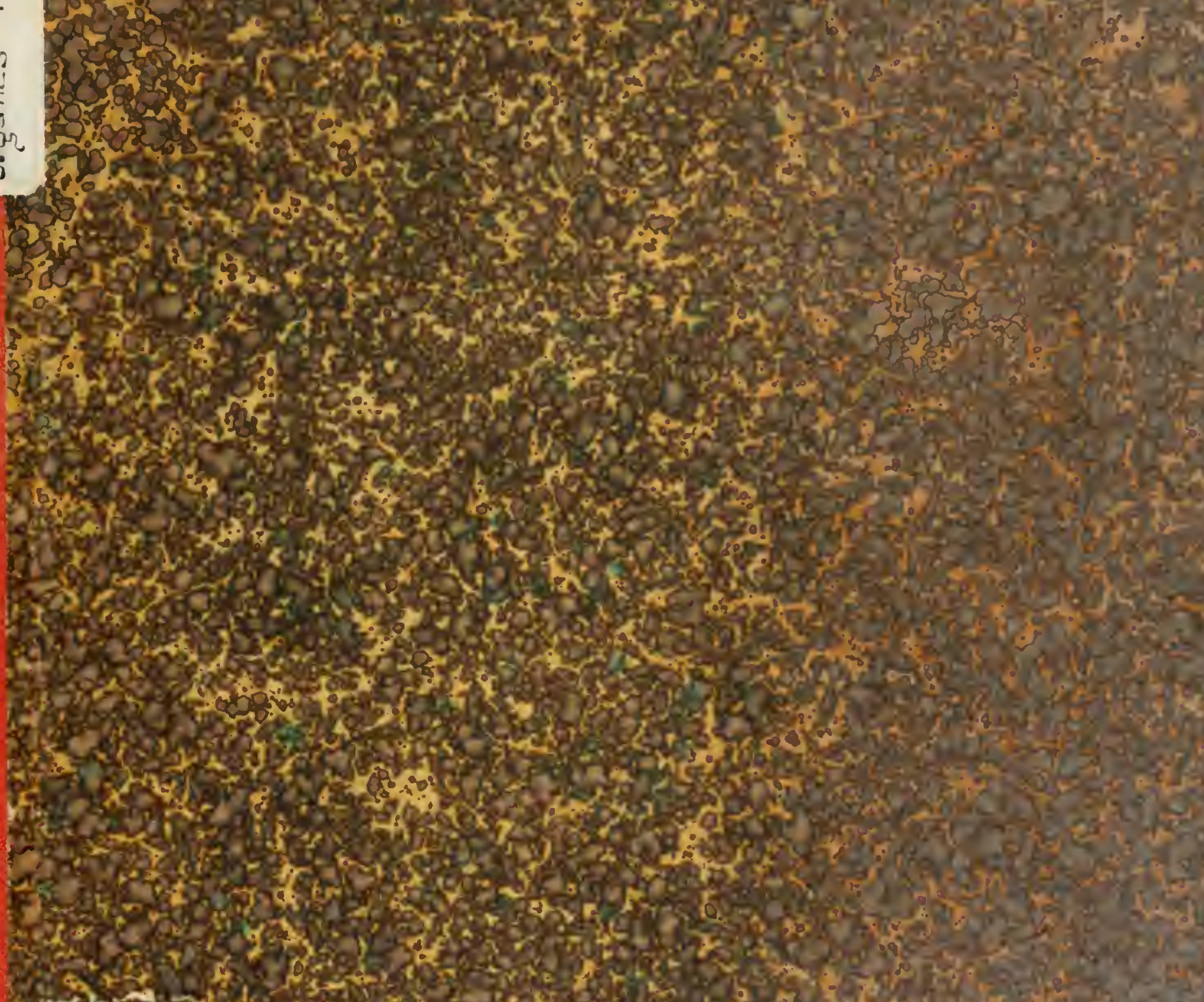

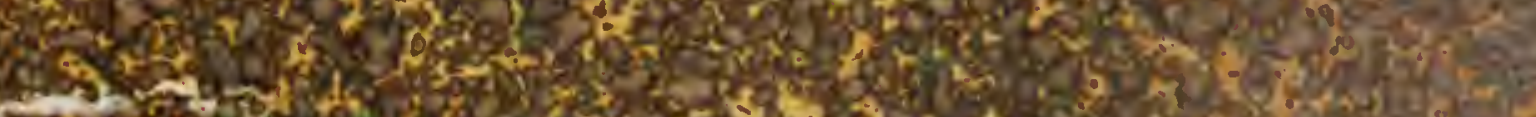

300 a

30 s.

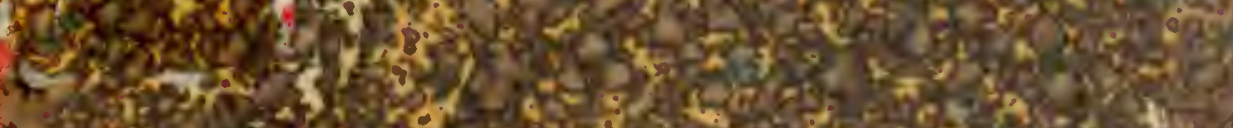

y.2.

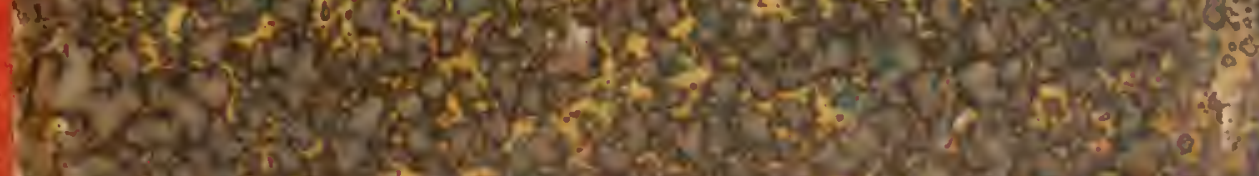

S 


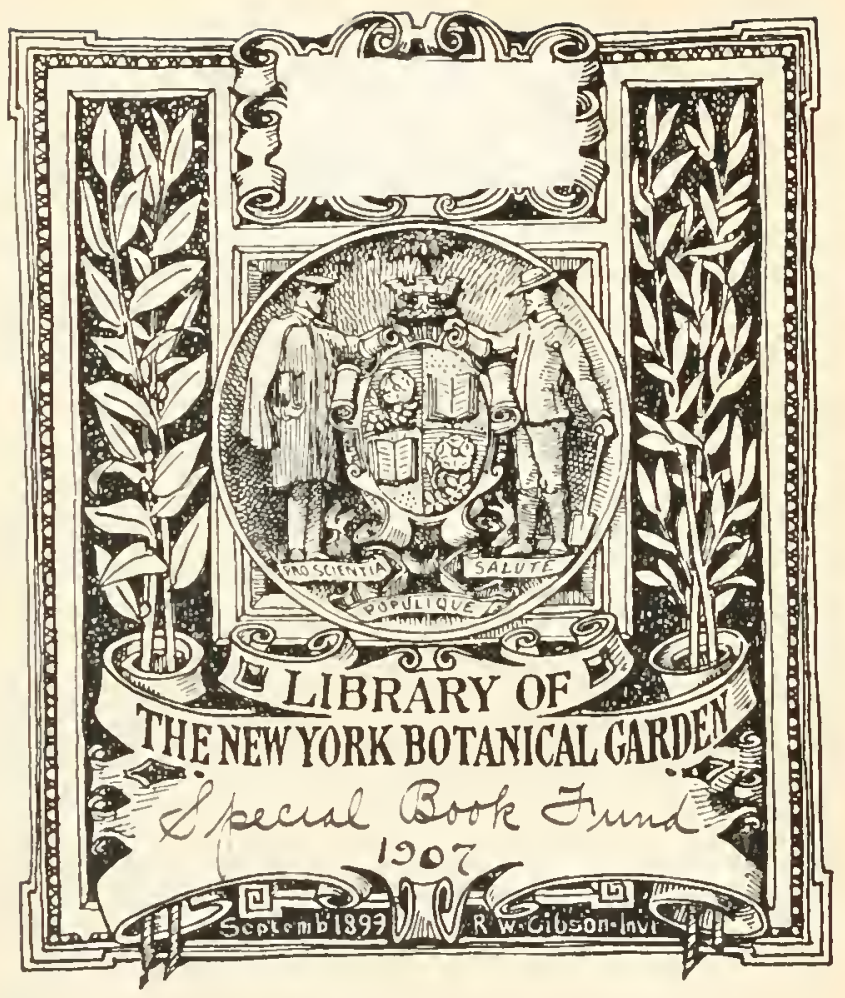












\title{
CONSIDERATIONS
}

SLI:

\section{LES FONCIIONS}

\section{DES ORGANES FLORAUX \\ COLORÉS ET GLANDLLEUX;}

\author{
Shar e 1 Gidid-Tilix DUTAL,
}

D. M.; Professeur de Botanique ì la Faculté des Sciences de Montpellier; Correspondant de l'Académie des Sciences de l'Institut; Membre honoraire de la Soeiété de Phýsique et d'Histoire naturelle de Genève; Correspondant de la Société d'Histoire naturelle de Paris, de Ja Société d'Horticulture de Londres, des Sociétés Limnéennes de Paris, Lyon et Bordeaux, de l'Acadénie de Vaucluse, de la Société d'Agriculture, Commerce et $\Lambda$ rts de Narbonne; Membre de la Société d'A griculture du département de l'Hérault, de la Société de Médecine-Pratique et de la Société d'Histoire naturelle de Montpellier.

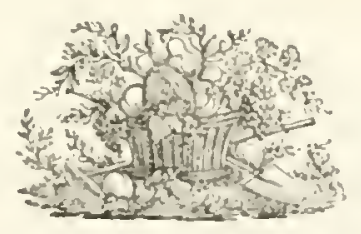

\section{LIURARY \\ NEIV YCliK \\ GOTAHICAL}

USRLER.

$\Lambda$ l'ARIS,

Chez GabON et Ce, Libraires, rue de l'École de Médecine.

A MONTPELTIER,

Chez les mêmes Imbañs, Grand'hue.

$1 \$ 29$ 



\section{CONSIDLRATIONS}

SUIR LLS TOXCTIOXS

\section{DES ORGINES FUORAUX}

\section{COLORES OU GLANDULEUX.}

Dixs ma dissertation sur la nature et les rapports de quel ques-mus des organes de la flem, jai cherelé à prouver que ceux de ces organes, qu'on a long-temps regardés comme anomaux, font partie de lenrs verticilles reguliers e principalement de ceux qui portent les antheres. l'our cela, j’ai táché de montres quion wouve toutes les formes intermédiaires entre l'étamine la plus complète ec le corps glanduleux, et quon voit ces diver's organes occuper tour it tour les mèmes positions.

Les pétales, les androphores, les lépales membraneux ou pétaloüles, ne som, arons-nous dit, que des modilications d'mu seml et même organe (1). Toutes ces parties, ordintirement colurtés, out une contexuse analogue, et sontassez généralement caractérisées par le velonté de leur surface, les couleurs dont elles se parent, la dirersité des odcurs qu'elles exhalent ex la production du nectar. On ne peut révoquer en doute leur analogie générale d'origine

(1) Considération sur la nature et les rapports de quelques-uns des organes de la fleur, pag. 48. 
Ainsi ce célèbte pliysiologiste, ì qui la science doit tant de recherches sur l'usage des organes des végétaux, se borne à des conjectures sur les fonetions des pétales (1).

Necher, en 1785 , choisit trois boutons bien formés d'Aquilegia anlgaris et de Cheiranthus Cheiri; il en retrancha avec soin le calice et les pétales, et eut en mème temps la précaution de garantir les ćtamines et les pistils de l'action des corps extérieurs; les étamines se développèrent et répandirent leur poussière sur les pistils, mais il n'y eut point de graines fécondes. Necher reconnaît Iıi-mềne que cette stérilité pouvait être l'eflè de quelque blessure faite au pistil pendant l'opération (2).

Les pétales des légumineuses, déjà hors du calice ou entièrement développés, ont été conjés par Senebier sans mire à la fécondation. Ce pliysiologiste a pratiqué le même retranchement avee les mèmes résultats sur les Poiriers et plusieurs autres plantes qu'il ne nomme pas; mais, s'il fau l'en croire, les fleurs du Cerisier nont donné ancun fruit après la suppression de leurs pétales, ou même après leur mutilation (5).

Pontedera vit périr les graines de l'Aconium luteum dont il avait retranché les singuliers pétales regardés comme des nectaires par Linné (4). Mais Mustel assure que, si on ne supprime les pétales qu’à une ćpoque avancée de la floraison, l'embryon, loin d'eu souffrir, s'accroît avec plus de rapidité (5).

Voilà, je crois, tout ce qui nous a élé appris jusqu'ici sur l’usage des pétales; l'étude des fonctions des lépismes n’est guère plus a vancće.

(1) Physique des arbres, I. liv. Ill. p. $27 \mathrm{I}$.

(2) Acla academice Theodoro Palatina, tom. 5. Daprès Senebier, Plyssiol. tom. Il. p. 57 .

(3) Sen. Phys. t. II. p. 56 et 57.

(4) D'après Sencbier, Phys. t. Il. p. 42.

(5) Mustel, ouvr. cit. 1. 1. p. 178, 181 et 266. - Senebier (Plıysiol. p. 57 ), en rapportant celte asser(ion de Mustel, lui fait dire tout le contraire. 
Pontereda (1) a soupenne que la liqueur mielleuse qui suinte des nectaires, et quon trouve acrumulie dius les cavitis eles

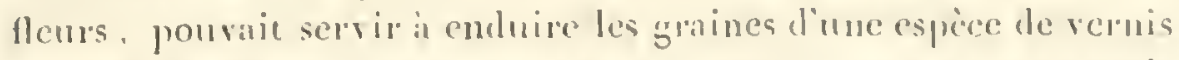

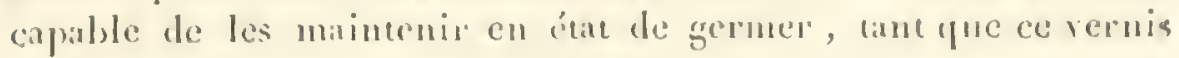
se conserve sins altération.

$\Lambda$ pen pris a la mime éporpue, queldues plypiciens ont punsé que les insectes, autres par le nectiu eles fleurs, occasionaient par leur piquare la dispersion de la poussiere fécondante. Corte

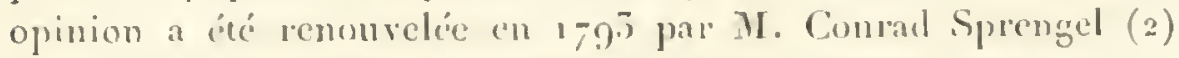
qui lia expose aver de nombrenx dérelopjemens. Selou lni, les insectes, qui se nomrissent de nectar, farorisent la férondation, soit en excitant ou en seromant les étamines, soiten portant Je pollen des fleurs milles sur les fleurs femelles des mémes espéces, et ils déreminent des hybrides an posane sur les stignates de certaines fleurs, du pollen enlevé ì des fleurs d'espéces difrérentes. Il croit ce mole de fécondation néessaire dans certains veggéans; anssi pense-t-il que les taches ou hosses particulicres quion observe dans guelques corolles, ont pour utilité d'indiquer ans insectes les nectaires yui ponraient leur échapper, on les flems sm lespuelles il est utile quils se reposent.

Comme Ies plantes ne parnissent pas soufrir du larein que leur font tant d'insectes, Duhamel a cru probable que le miel un nectar n'était fu'un excréncht des rígétanx (3).

Senclier, en parlant des chamines, a avancé, sans développemens ni preures, que leurs files sont des filtres à travers desquels jasse l'aliment des poussières, et que les sucs qu'elles reçoivent doiven étre préparés par le calice, par les pétales, et par un corps glanduleux quon observe à leurs pieds. Mais nous devons ¿t look de observations plus positives et plus intéressantes sur

(1) Anthologia et Disserlationes; d'après Duhanel.

(2) I rol. $80^{\circ} 17 y^{3}$, cité par M. De Cand. Organ. p. 538.

(3) Dubamel, Physs. I. liv. 111. p. 235. 
les organes qui nous occupent (1). Cet auteur a très-bien remarqué que le nectaire tombe arec les parties caduques des fleurs (2), et qu'on ne trouve jamais de suc mielleux dans le bouton; il a vu que la présence de ce suc ne se manifeste qu'après l'épanouissement de la flem, lorsque les corps glandulenx qui la produisem ont acquis leur plus grand accroissement, et que cette époque est aussi celle du développement le plus complet des anthères; enfin il a aussi très-bien observé que lorsque les parties de la génération se flétrissent, le nectar diminue; aussi présumet-il qu'il est absorbé par des vaisseaux particuliers, et qu'il favorise les premiers développemens de l'embryon.

Les auteurs les plus récens ne parlent pras de l'usage des neetaires, et M. 'Turpin pense que leurs fonctions pliysiologiques doivent être peu inportantes (5).

Telles sont, à ma connaissance, les diverses opinions des naturalistes sur l'usage des parties colorées des fleurs; elles se réduiscnt done anx suivantes: I. l'usage des pétales est de protéger les étamines et les pistils; $20^{\circ} \mathrm{i} l_{s}$ servent i préparer une nourriture appropriée aux besoins des antlıères el des jemnes fruits; $5 .^{\circ}$ les nectaires ne sont que des organes excréteurs; 4.” ils séerètent une matière qui est absorbée pro le fruit, et forme une sorte d'enduit protecteur autour des graines ; 5." leur fonction consiste à attier les insectes qui contribuent puissamment ì la fécondation soit en exeitant les étamines, soit en se cliargeant de leur pollen qu'ils uansportent sur d'aures fleurs; $60^{\circ}$ lenr importance physiologique est de peu de valeur; $70^{\circ}$ enfin ils ont ponr usage de sécréter un nectar dont l’absorption favorise le déreloppenent des étamines, et contribue à celui des parties contenues dans lovaire.

(1) De Neclariis Geraniorum. D'après Senebier, Plıysiol. 11. p. 41.

(2) Roth n'appclait neclaire que les organes qui ont été désignés sous ce nom par Linné; aussi ne rait-il pas mention de ceux qui sont persistans et qui ont été plua sourent signalés sous le nom de disques.

(3) Turpiu, Gram. et Cyp. l. c. p. 4-8. 


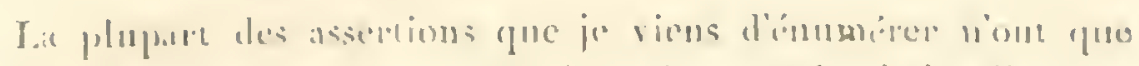

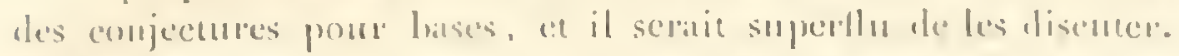

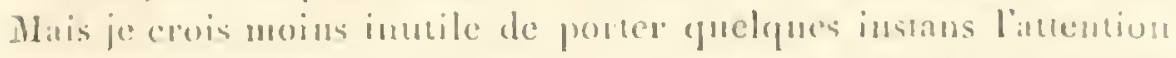

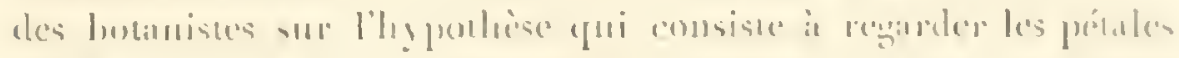

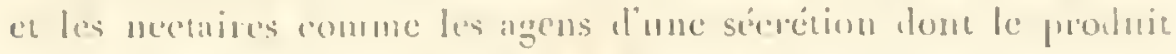
est restiné it la nutrition des anthires el des jennes ovules.

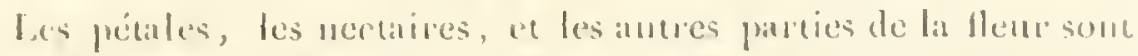
deiji formes dans le bunton. Daus les flenes de l'Aunadier er

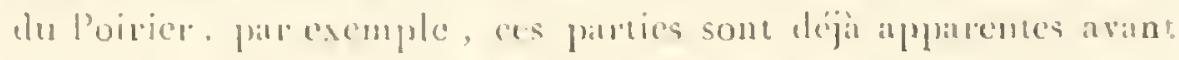
le printemps qui doit les soir ciclore. A l'époque qui préciele immuliatement celle de l'úpunoussement de lat lleur, les piales sone repliés dans le bouton, le lepisme glanduleux qui tapise le whe dn caliee (disque on nectaire prirgyne) est see, gremu

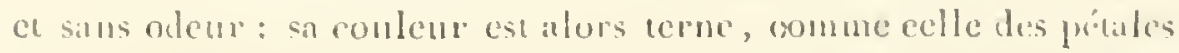
daus le mime moment: mais dès que l'atratmosphérique se troure en contace immédiat arec ees parties, les pétales śétendent et et sétalene en dehors du calice. Ie lépisme prend de laceroissentent el l'aspect extérienr de ces deus organes commenee at

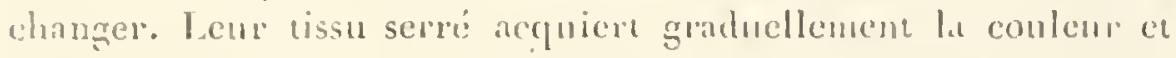

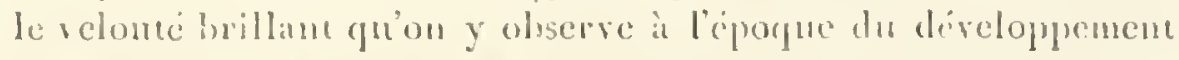
complet des antrieres, el la surface du lépisme d’abord entièrenent sèche est alors hubrifréc par une liqueur "paisse qui exhale lodem. le micl que tout le monde comait. Les étamines ontelles rempli lemrs fonctions, elles ne tardent pas à se llétrir; les pétales se dessiechent et tombent; la sécrétion du lépisme se tatrit progressirement, et celui-ci dépérit ì son tour avec les orgares fécoudilns qu'il acconpragne.

Lorsque lon casse le lépisme diune flent l'Amandier arant l'épranourssentent, on roil que ses portions séparées ont la consistance et l'aspeat des parties de certaines plintes qui renferment beaucoup de fécule, conme les pommes de terre, les ubereules du soucher comestible, ete. Cene grossière analogie me fit penser d'abord que les jeunes lépismes deraient anssi contenis de ta fícule; mais, dis-je bientòt, s’il en est ainsi, puiseque ils som 
couverts d'un liquide u'ès-sucré lorsqu'jls ont été soumis pendant quelque temps à l'action de l'air, ne se passe-t-il pas ici un phénomene semblable it celui quion observe dans lit germination? E'action de l'air sur la fécule laumide du lépisme n’a-t-elle point pon ellet sa conversion en m liquide sucré comme dans les graines yui gernent, et ce liquide n'estil pas une somte de sang régétal qui, dans la lloraison, fonsnit an pollen et amx jenncs ovnles les matériaux nécessajres à leur nutrition, comme dans la germination il domne ceux que nécessite le développement de la gemmule?

Une seule expérience, quoique grossière, m’a paru domer quelque probabilité de plus à cette hypothèse. Les appendices glandnlenx du spadix de l'Arum italicum ont leur surface tr'sferme, consistante, et d'une conlenr blanche fort terme, avant la déhiscence des antières. A cene époque de la durée de ces Heurs, j’ai séparé de leur lose les appendices terminaux d’un assez grand nombre de spadix, et je les ai trajtés comme les pommes de terre dont on rem extraire la fécule; une quanticé assez notable d'amidon très-blane s'est déposéc an fond du rase; 7o grammes de pâte formée par les appendices hroyés ont donné 5 grammes de fécule dessécliée à la température de 20 degrés. Cette expérience a été rópétée, et la seconde opération a produit un résulut analogue ì celui de la première.

Des quantités égales d'appendices glanduleux de la même espèce de Gonet, ont été séparés des antres parties de leurs cluâtons, après l'émission du pollen qu'on troure alors en grande quantité au fond de la spathe qui enveloppe l'appareil génital de ces plantes. A cette époque de lcur durée, ees appendices ont acquis une conleur jaune plus foncée, la consistance de leur tissu est moins ferme, et leur surface, sans être précisćment humide. est lisse et phus luisante. Thaités comme ceux d'un âge moins avancé, ils nount point donné de fécule; on a retiré seulement du fond du vase daus lequel on avait placé l'ean qui avaiı lavé la pâte formée par ces appendices, une petite quantité d'une matière grisâtre qui 


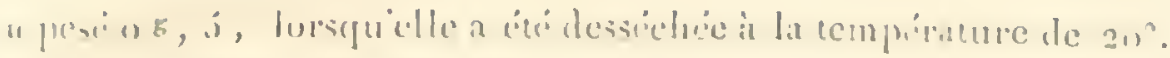

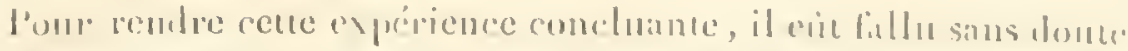

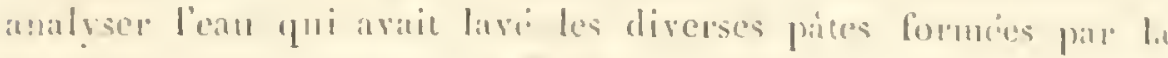

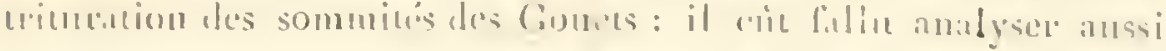

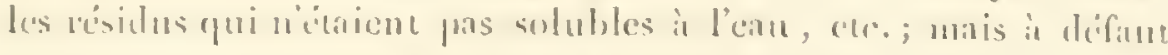

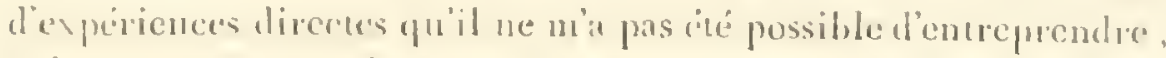

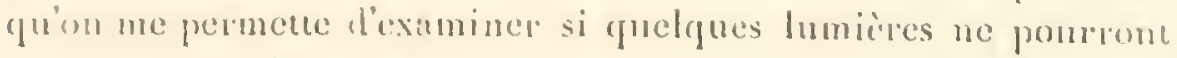

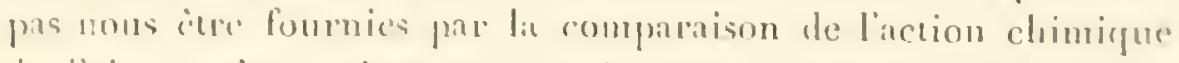

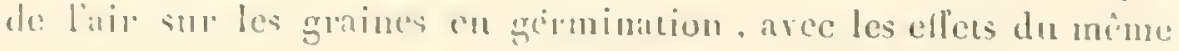
thaide sur les thenrs qui se devoloppente

()n ne pent soecuper des phénemines chimiques de la vergri-

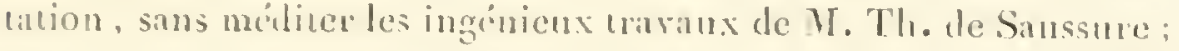

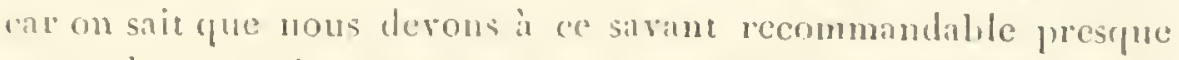
tuthes les commissmees que nous avons sul cot incéressant sujet: atussi les failsyui lomment lieu aux ronsidérations suivantes, sont-ils puisés pour la plupart dans les ouvages de cet hahile chimiste.

'Trois conditions sone indispensables pour gue la germination sopere: 1." une température au dessus de o ( celle de 1 a est regarulée comme la plus fivomale); $20^{\circ}$ un degré comenable

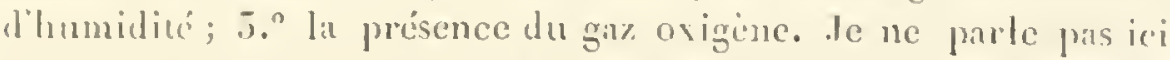
de la soustanction à une rive lumiere, puisfue celle-ci ne firt yue retarder le phénomine saus l'empéclier ruand les autres comditions some remplies, et que, d'un autre cóté, M. Th. de Sirrssure a prouré que la lumière ne muit a la germination qü ir raison de la chalent quelle produit (1).

Les mémes conditions sont nécessaires pour le développencunt des urganes lloranx colorés ex glanduleux: 1.0 on ne voil fuint ćclore de fleurs que la tempéraure du milien dans lequel clles se troment placées ne soit atu dessus de o (la température de 10 ¿ ju", considéric comme la plus firsoralole a la germination, est aussi celle de la floraison du plus grand nombre de plantes); 2. pour que cenc lloraison ail lien, la sève ascendante duit

(1) Recherches chimiques sur la vegéhation, pag. 23. 
fournir à la fleur des matières aqueuses sans lesquelles ses parties ne peuvent pas sépanouir; 5. "les fleurs, mème celles des plantes aquatiques, ne se dévcloppent pas dans des milieux déponvus de gaz oxigène (1). "Observons encore que d'un côté, d'aprés les assertions et les expériences de 'Tourmefort, Senehier, etc., les pétales ue paraissent contribucr à la nutrition des organes sexncls que dans leur jeunesse, époque à laquelle ils sont habituellement recouverts par les verticilles qui les cutourent: et que, d'un antre côté, les lépismes, situés dans le fond des flemrs, an dessous des étamines et des oraires, somt ordinairement soustraits ì l'action d'une Iumière trop vive; si, toutefois, la quantité de giaz oxigc̀ne détruite par les flemrs est plus grande au soleil quä l’ombre, cela tient sans donte à l'élévation de la température qui, comme on sail, augmente ceue destruction (2).

La fleur se trouve ainsi placéc dans l'atmosphère, avec les mêmes conditions que la graine dans le sol qui lui convient; olsservons ce qui se passe dans les deux cas.

S. I. Iorsqu'une graine en germination a acquis le degré de chaleur ei d'humidié convenable, elle cnlève à l'air une portion de son oxigène et lui rend unc ćgale quantité de gaz acide carbonique: or, comme un volume de ce dernier gaz ígale un volume d'oxigène, il est civident que celui-ci prive la graine d'une portion de son carbone. Des changemens s'opèrent dans l'albumen et les cotylédons, et en v'ésultat, la fécule qu'ils renfermaicnt, se trouve remplacée par me matière sucrée.

Une fleur en s'épanouissant emprunte de même à l'atmosphère une portion d'oxigène, pour lui rendre un ćgal rolume de gaz carbonique, et ici il y a encorc formation d’un licruide sucré, vraisemblablement aux dépens de la fécule contenue dans les pétales ou dans les lépismes.

(1) Th. de Saussure, Ann. de Physique et de Chimie, tom. 21, pag. 279. (2) Th. de Sauss. Ann, de Plirs, et de Chim. tom. 21, paz. 282. 


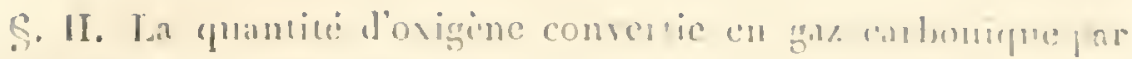

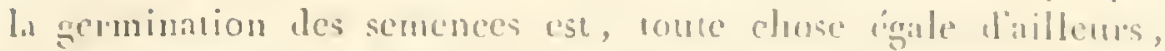

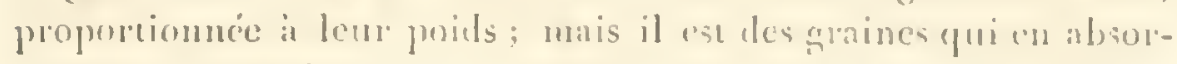

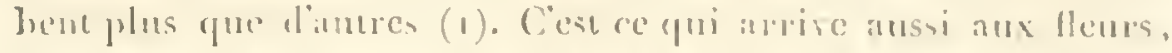

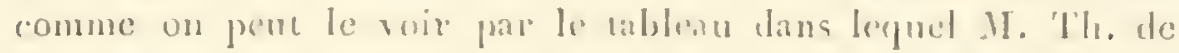
Sanssure fait ronnaitre le volume de ga\% oxigrine consumé pare des lieurs, compare an volume de ces dernieres pris pour unité(2).

S. III. Il y a production de chalene pendant la gemontation; re phénumene est du muina ivident dins la proparation de lit

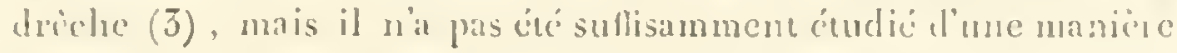
gencirale.

La température est aussi angmente pendant la lloraison, an moins diuns queleques cas. Par ses intéressantes expériences sur ce sujet, M. de Samssure a, non-sentement indiqué de quelle maniere se manifeste la chaleur doja observe daus les organes floraux des Couets, mais encore, il nous a fait connatre: 1. que d'antres fleurs ont aussi une chaleur propre, qroigue a un degrémoins élevé que celle des frum (4) ; 2." qu'un grand nonthe n'a pas une comprératue dillérente de celle de l'atmosplicre; et 5.0 que heauconp d'autres, bien loin d'ère chandes, sont plus froides que l’air, ì raison de leur évaporation. Cetce diversité daus la production de la chalentr pendant la floraison est peruirre phus apparente que relle, puisque, ainsi que l'ohscrie Més-hien MI. de Satussure, les circonstances indéterminćes. telles que l'évaporation, Je rayonnement, la fieulté conductrice, etc. modilient sensiblement leffec calorifigue des flenrs, et l'on pourait admette qu'une delles qui parait froide, possiede me source

(1) $T h$. de Sizuss, Rech, pag. 13.

(a) Ann. he Pigs. et de Chim. tom, 21 , pag. 283.

(3) Thomson, iom. IV. pag. 3ił.

(4) Celles de la Courge (Cucurbilu maximn), de la Bignone de Virginie. Jignomir radicans, de la lubéreuse, Polyantles tuberosa. De Sauss. Ar:n., 10m. XX1, pag. $29^{5}$ el suirantes. 


\section{$1 / 1$}

de chatenr aussi abondante quime autre menr qui est chande it min falle degré. Ainsi, quoique l'étude de la chaleur des flems soil plus arancée que celle du dégagement du calorique pendan la germination, nos comnaissances sur ces denx phénomènes doivent ère porties plus loin, avant quion puisse en conclure que la chaleur, produice dans les deux cas, est due ì la même cause; mais il n'en est pas moins vai qu'elle se manifeste quelquefois daus les deux circonstances, et que l'étal de la science neest gù̀̀e plus arancé dans l'une que dans l'antre.

S. IV. La plus grande partie du liquide sucré produit par la germination est absorbé par la radicule pour étre transmise bientôt après an premier bourgeon de la planie silté an-dessus des cotylédons, et une antre portion de ce liquide se perd dans les enveloppes de la graine.

Puisquil y a similiude entre les plúnomènes qui se manifestent pendant la conversion de la fécule de la graine en matière sucréc, el cenx rui coüncident avec l’excrétion du nectar et les antues changemens qui sopèrent pendant la floraison, n'est-il pas vaisemblable qu'un liquide sucré, fourni par les organes glandileux et pétalö̈des des flem's, est d'ahord absorbé par les vaisseanx de lenr base pour étre porté immédiatement après aux antières et aux jemes ovules qui sont placés, relativement aux pétales et aux lépisnes, comme la gemmule, relativement aux cotylédons? Le nectar, répandu sur la surface du lépisme glandulcux, et recélé plus tard dans les concavités des fleurs, ne doit-il pas être considéré comme une sorte d'excrétion de matérianx surabondans, puisqu'il peut ête enlevé et dereni. l'aliment d'une foule d'insectes sans elles nuisibles pour les fleurs qui le produisent (1)? Si l'hypothèse que je discnte acruerrait

(1) La liqueur sucrée que recèle habituellement le fond de la corolle du Bignonia radicans, est quelquefois si aboudante, qu'elle empêche le développement de la chaleur daus cel organe; mais lorsqu'on a extrail ce liquide arec du papier brouillard en le plongeant jusqu'au fond de la corclie, celle 


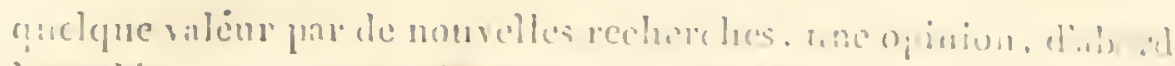

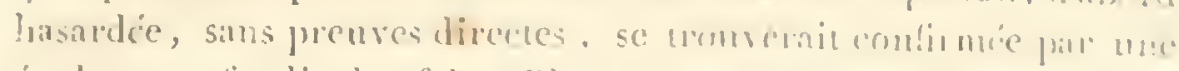

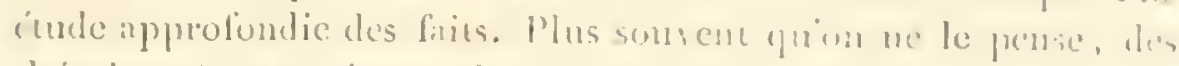

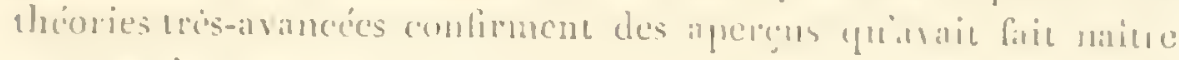
un premier evamen.

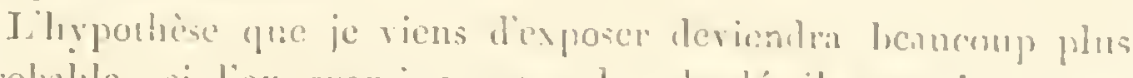

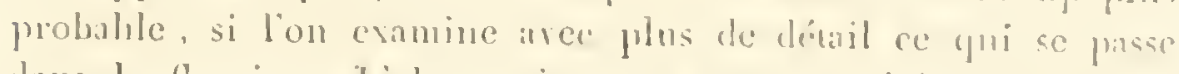

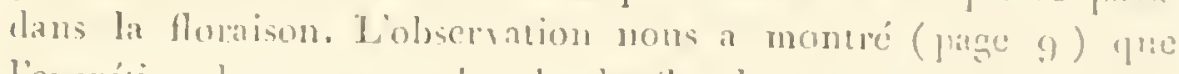

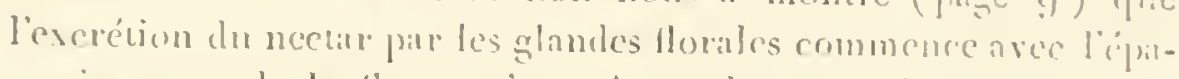

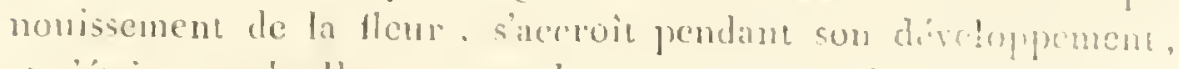
et séteint graduellement avec les organes sexnels dont ies colpe glanduleux semblent partager les fonctions. Nous allone wor $1 . "$

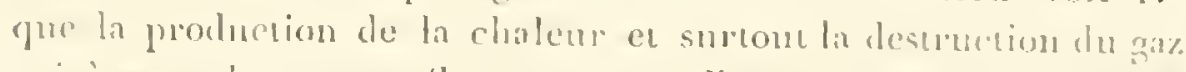
migene par les organes llorans, sone d'autant plus consicléblles que les parties sur iescuelles ees plrónomèncs subserrent sont plus glanduleuses: les mimes fitts nons montreront itusi qune les mèmes flićnomines chimigues atteignent le maximum de lem* intensite: it lóproque de la plus grande aetivité de la fícundation et de la function des neetaires. 2.0 Tons examincrons cnsuite les propriétés générales du liquide sncré que produisent ces dernier.

5. I. Mu Riappont des phénoménes chimiques qui se munifesten pendant la floraison, arec la nature des organes floranx: coloress el "̈lundulcux, "les divers degrés de leur décloppenent. Dans ancune lleur, l’organe gland nlenx n'est aussi développé que celui des Goucts: ćest anssi celui đ[ui manifeste le plus de chaleur. On sait que M. de Lamarck (1) a le premier remarqué que les spadix des arum iulicum et maculaum, à l’époque de leur plus gliund développement, acquierem une chaleur considérable. Sencbies' a observé

dernic̀re produit souvent un effet calorique qui n'était pas sensible auparavant. (De Sauss. Ann. 21, p. 29.7) Ne pent-on pas penser que les iusectes, en enlevant le nectar surabondant, produisent quelquefois des efrets aualogucs, et favorisent conséquemment les fonctions des nectaires?

(1) Flor, Grans. 1. $0^{\text {re }}$ (d. page . 
que cette chaleur commence à être sensible quand la sjathe s'ourue entre trois et quatre henres après-nidi, qu'elle atceint son maximum entre six ce huit henres du soir, et disparaît ensuite gradnellement ponr ne plus se manifester. Ce physiologiste a vu qu'en appliquant à la surface du spadix de l'Arum maculatum la boule d'un thermomètre, cet instrument indiquait nue températmre supérieure de sept degrés R. à celle de l'air environmant (1).

Des effets bien plus marqués ont été obtenus par MI. Mubert, ì l'Hle de France, arec l'Arum cordifolium. Un thermomètre, placé au centre de cinq spadix, a indiqué une température de 44 degrés, et lorsqu'il était entouré par douze de ces chatons, il s'estélevé à 49 degrés $1 / 2$, tandis que la température atmosphérique nétait que de 19 degrés; la plus grande chaleur de cette fleur avait lieu au lever du soleil.

Les parties mâles de six spadix de la même esprèce, détachées des appendices terminatux et des fleurs femelles, furent aussi placécs antour d'un thermomètre; la température ne dépas̉sa pas 41 degrés. et les parties femelles n’ont mu l’élever dans les mêmes circonstances qu ì jo degrés. M. Hubert a vu que cene chaleur cessait, soit lorsquion enduisait les spadix d'empois, soitlorsqu'un les plongeait dans l'eau ou le vinaigre, et qu'elle reparaissait en rérablissam le contacı de l’air. Cet auteur a reconnu, de plus, que ces cliatons viciaient l'air atmosphérique (2).

Les expériences que nous venons de rapporter, prouvent sans donte que les Arum ne détruisent de l'oxiģène et ue développent de la chaleur qu'antant que leur surface glandulense est en contact arec l'atmosphière; mais cette chaleur n'est produite qu'à une époque déterninée de linflorescence, celle du plus grand accroissement des organes floraux, lorsque l'émission du pollen commence ou va commencer. Si à ces cousidérations, on ajoute que

(1) Sen. Plyys, vég. vol. 3. pag. 3, i,

(2) Extrait du voyage de Bory-S.'-Vincent, journ. de phys. tom. LIX. pag. $280,-T h$, de Sanss. Ann. de phys, et de chim. 2r. pag. 285. 
les partios mâles de l'strum cordefolium ont produb une chalent plus considerable que les arganes femelles des mimes planes, on sera porté ì penser que le développenent ex l’úmission de la ponssiere fécondante prement joner un grand rôle dans re renanqualule phénomine. C'ést ce que nous ont appris plus pusitivement les experiences de M. 'Th. de Saussure, dome nous allons rappeler les risultats.

Cenx qui sont consigués dans le tablean suivant, montrene que la destruction du gazorigene de l'air est plus grande an moment de l'entier déreloppement des fleurs qu'avane leur épanouissement; ils montrent aussi quélle est moins considérable à l'époque oi elles se llétrissent.

\begin{tabular}{|c|c|c|c|c|}
\hline \multirow[b]{2}{*}{ ESP li C E S. } & \multirow{2}{*}{$\begin{array}{l}\text { DUREL } \\
\text { de claque } \\
\text { cxpérience. }\end{array}$} & \multicolumn{3}{|c|}{ GA\%, OXIGLNE DETRUIT } \\
\hline & & $\begin{array}{l}\text { par } \\
\text { le bouton. }\end{array}$ & 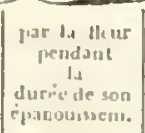 & $\begin{array}{l}\text { par ls tleur } \\
\text { en se } \\
\text { Ietrimb? }\end{array}$ \\
\hline Passiflora serratifolia..... & 12 heures. & 6 fois son rol. & 12 & 7 \\
\hline Mlibiscus speciosus...... & 24 & 6 & 8,7 & 7 \\
\hline Cucurbita maxima, heur mäle. & 24 & 7,4 & 12 & 10 \\
\hline Arum italicum. Spadix [roid(1) & 24 & 5 \ 6 & & \\
\hline Spadix chaud. & & & 30 & \\
\hline 24 heures après & & & & 5 \\
\hline
\end{tabular}

(s) Je place ici l'expérience faite sur cet Arum par M. Th, de Saussure, parce que je suppose qu'il a été exaniné avant le développement complet des anthères; il en est peut.être autrement. Il serait utile et curieux d'observer avec précision quel est l'ćtat des étamines qui coïncide avec la production de la chaleur, et conséqucrument avec l'avidité des spadix pour l'oxigène. 
Des fleurs réduites à leurs organes génitaux, c'est-à-dire aux étanines, aux lépismes, au pistil et au vrai réceptacle, ont consımé plus d’oxigène que celles qui sont entières, comme le témontrent les faits suivans.

\begin{tabular}{|c|c|c|c|}
\hline \multirow[b]{2}{*}{ ESPECES DE PLANTES. } & DUREE & \multicolumn{2}{|c|}{ GAZ OXIGÈNE DÉTRUIT. } \\
\hline & $\begin{array}{l}\text { de cliaque } \\
\text { expérience. }\end{array}$ & $\begin{array}{c}\text { par les fleurs } \\
\text { entières. }\end{array}$ & $\begin{array}{l}\text { par } \\
\text { les organes } \\
\text { sexuels. }\end{array}$ \\
\hline Cheiranthus incanus...... & 24 heures. & 11,5 fois son vol. & 18 fois. \\
\hline Tropœolum majus....... & $n$ & 8,5 & 16,3 \\
\hline Cucurbita maxima, fleur mâle. & 10 & 7,6 & 16, \\
\hline Hypericum calycinum .... & 24 & 7,5 & 8,5 \\
\hline Hibiscus speciosus. ...... & 12 & 5,4 & 6,3 \\
\hline Cobœa scandens........ & 24 & 6,5 & 7,5 \\
\hline
\end{tabular}

On voit par le tableau précédent, que la différence entre la quantité d'oxig̀ène détruit par les fleurs entières des trois premières espèces, et celle qui est consumée par leurs organes génitaux, es beaucoup plus grande que la différence qu'on observe entre la destruction du même gaz par les fleurs entières des trois dernières espèces, eı celle qui esı produite par ces mêmes fleurs dépouillées de leurs enveloppes. Deux causes peuvent avoir contribué à cet effet: $10^{\circ}$ l'Hypericum calicimum n'a point de lépisme glanduleux, et celui-ci est très-peu développé ( seulement ì la base du calice) dans l'Hibiscus speciosus, tandis que des glandes ou des lames nectariféres considérables s'observent dans les fleurs des Chieranthus, Tropeolum el Cucurbita. 2. Le Cobaa scandens possède, il est vrai, un lépisme assez grand; mais celui-ci, d'une consistance très-ferme, persiste après la floraison, ce qui fait 
suppraser que son action sur l'atmosplitire doit dire lente et peu sensible. Les lépismes des Cheiranthus, Tropurohum eq Cucurbiun sunt, an contraire, asse\% suceulens et, se flétrissent en méme templs que les étamines.

Une autre expérience de M. de Saussure prouve phus directement, que la destruction du ga\% oxigène est beatucoup plus grande par des étamines qui existent simulanément avec un lépisme, que lorsque ees étamines en sont sciparées. On sait que celles des courges sont formées pal trois androphores sondés, élargis ¿̀ leur hase et terminés par de grandes anthères anfractuenses: on sait aussi qu'au centre du tuhe qu'elles forment, on observe un grand nectaire en godet (1). Nous arons ru ( page 17) que cet appareil génital, dépourru de corolle, a consuné en dix henres scize fois son rolume de gaz oxigène. Un poids égal d'étamines détachées par une section faite an-dessus de la base des androphores, n'en a détruit que 12,7, dans le néme temps.

Les fleurs màles entières du Cucurbita maxima nont consumé quenviron luit rolumes d'oxigène pendant que leurs étamines et leurs lépismes en ont détruit seire (page is). Il paraît done évident que ces dernières vicient l'air beancoup plus que les corolles; éest ee que confirment d'autres faits encore plus concluaus.

La spatie d'un spadix chaud d'Arum maculatum a détuit en ringt-quatre lieures 5 fois son rolume d'osigène.

L'appendice terminal de la même plante. . 5o fois.

Les organes sexuels. . . . . . . . 352 fois.

Un Arum dracunculus entier a opéré dans 24 heures la destruction de 35 fois son volume de gaz oxigène: sans sou cornet, il en a consumé 57 .

Une antre llew de la même plante, du même poids que la prennière, a été dirisće en quatre portions.

(1) Cucurbita. Malpighi, Op. omn. lab. XXXI'I. fig. 226. Lépisune intérieur, D; androphore, C; autheres. H. F. L. G. J. K. 
1. Ie cornet isolé a détruit la moitié de son volume de gaz oxigène.

2. L'appendice rerminal. . . . . . 26 fois.

5. Les organes mâles. . . . . . . • . 155

4. ${ }^{\circ}$ Les organes femelles. . . . . : . 10 (1).

Rappelons-nons maintenant que les anthères des Arum, comme nous l'avons vu aillenrs (2), naissent d'un tissu glandulenx analogue à celui qui jecouvre l'appendice terminal, et il résultera, je pense, des faits qui viennent d’ètre énumérés, que les anthères réunies à des corps glanduleux, somt les organes floraux qui détruisent le plus d’oxigène, que les tissus glanduleux isolés tiennent le second rang sous ce rapport, et que les organes pétaloïdes viennent ensuite; mais comme d'antres expériences de MI. de Sanssure (5) pronvent encore que les fenilles (à l'obseurité) consument moins d'oxigène que les fleurs, on pent conelure, ce me semble, de ce qui précède: 1. que généralement la destruetion de l'oxigène par les organes floraux est en raison inverse de la matière rerte qu'ils renferment, et en raison directe de leur masse glanduleuse ; $2 .^{\circ}$ que le moment de leur plus grande intensité d'action est celui dn déreloppencnt des étamines.

Quelques antres observations de M. de Sanssure semblent confirmer cette opinion : cet ingénieux physicien n'a point tronvé de différence notahle cntre la destruction de. l'oxigène par les organes génitaux et par les flenrs entières, dans le lis blancet dans le Passiflora serralifolia (4); mais ces fleurs n'ont point d'organes glandulenx, ne possèdent qu'un petit nombre d'étamines, et leurs organes pétaloïdes sont très-développés : n'est-il pas vraisemblable que la plus grande surface de ces derniers a

(1) 'Th. de Sauss. Ann. de Physs. et de Chim., tom. 21 , pag. $28_{7}, 288$, 289.

(2) Cons. sur la nat. et les rap. de quel. uns des org. de la fleur. p. 122.

(3) Mémoire cité, page 283.

(4) Ouvrage cité, page 2q1. 
compensí l'accion plus incense des organes máles, qui ne pourait

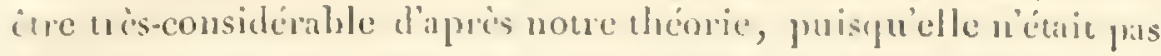
soutenue par la présence d'un corps glanduleux.

11 y a mienx; it volume ingal les flems douhles de la girollé

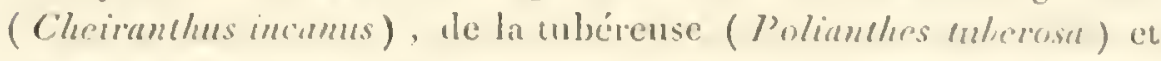
le la capucine ( Troprolum majus), ont consume moins d'oxigène que les theurs simples des mûmes espéces (1). Cente diflïrence no provient-elle pats de re que res demiéres possedent des corps glanduleur et des étaninces fertiles, organes qui disparaissent dins les fleurs doubles pour faire place it des pétales. Comme l'observe trés-bien M. de Sinssure, cette destruction plus griande de ga\% oxigène par les llemrs simples les décompose elles-mènes, et explique comment leur régne est ordinarement plus combt que cehii des Heurs doubles, phénomène depuis long-temps connu "t sur lequel est fondéc la préférence quion donne ì ces dernières pour l'ornement de ros jarclius.

En résumé. puisque la destruction du gaz oxigène, et (dans queleque cas) la production de la chaleur par les organes floraux semblent dtre en raison directe de la matière glandulcuse quiils renferment; puisque ees phénoménes atteignent leur maximum d'intensité à l'ćpoque du plus grand déreloppement des anthères et de la plus gramle activité des fonctions sexuelles, n'est-il pas très-probulhle que laction du ga\% oxigène sur les corps glanduleux a un résultat farorable anx fonctions qui s'exécutent dans le même moment? Ce résultat n'est-il pas. comme nous l'arons lit plus lant, la formation de laliment yui doit ère fourni aur organes sexuels pendant la plus grande activité de leurs fonctions?

Admetons pour un instant que eette hypothèse cst entionement prourée: il deviendra évident que les jennes cotylédons, premières fenilles de la plante, qui forment le premier rerticille d’un régétal phianérograme (2), ont la plus grancle analogic de

(1) T\%. de Sauss., ouv, cité, pag. $283 \mathrm{et} 273$.

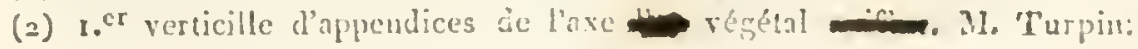


fonctions avec les lépales glanduleux qui forment le dernier (1) ou l'un des derniers verticilles de la mème série d'évolutions végétales. Rudimentaires les uns et les autres, dépourvus de matière verte, ils sont sourent aussi d'une consistance semblable et renferment de la fécule on des substances analogues. Acquièrent-ils leurs conditions d'activité, tous deux consument du gaz oxigène, dégagent du gaz carbonique et quelquefois de la chaleur ; leur fécule est remplacée par une matière sucrée, et celle-ci devient l'aliment des verticilles les plus voisins.

Les cotylédons et les lépismes diffèrent assez des organes de la tige pourvus de matière verte (feuilles, braetées, sépales, etc.), pour que l'on puisse attrihner à la diversité de leur forme celle qu'on observe dans leurs fonctions; cependant ces dernières présentent moins de différences, et surtout des différences moins tranchées qu'il ne le paraî au premier coup-d'ocil. Ites feuilles e les autres parties rertes des plantes n'enlèvent-elles pas, pendant l'obscurité, du gaz oxigène ì l'atmosphère pour le remplacer par un volume égal de gaz carbonique? Sous ce rapport, leur accion ne diffère de cellc des cotylédons et des organes floraux colorés, que par sá moindre intensité et sa marche interrompue. Mais les parties vertes végétales remplissent une atutre fonetion importante; elles absorbent du gaz acide carbonique pendant le jour, le décomposent comme elles décomposent celui qui est pompé par les racines, s'cmparent de son carbone et dégagent du gaz oxigène. En sappropriant ainsi le carbone du gaz carbonique, les organes rerts des végétaux paraissent agir comme les surfaces inhalantes des intestins sur les matières alimentaires avec lesquelles elles sont en contact; elles semblent préparer une sorte de chile qui, reporté de nouveau vers les feuilles, est décomposé par l'oxigène de l'air el transformé en une espèce de sang régétal destiné à la nutrition des parties. Cette seconde fonction, indépendante peut-

(1) Plusicursufteurs mâles (des de la courge, par exemple). 
Pue de la première, quoique exćcutce dans les mémes organes, est la scule qui soit commune aux parties vertes et a celles qui me le sont pas. Il semble que ces dernières. "prés avoir recu et accumule l'espéce de chile que les parties vertes peuvent exwaire, n’ont qu’ă le convertir en cambium ou sang végétal, qui, denns la fleur, doit servir immédiatement après à la nutrition des organes sexuels; et comme le développement de ceux-ci est souvent trèsrapide, on concoit que les parties qui ćlaborent leur nourriture doirent emprunter ì l'al une plus grande quantité d'oxigene dans un temps déterminé.

Mais la dillérence qui existe entre l'action des organes des fleurs et celles des feuilles n'est pas plus tranclsée que celle de leurs formes et de leur composition. Nous avons observé (1) tous les dégrés intermédiaires entre la glande et le pétale; nous avons également vu que par des unances insensibles, on passe des sćpales ou des pétales les plus colorés anx sépales ou pétales les plus verts (2), et lorsque ces dernicis composent seuls l'enveloppe florale, leur action sur l'atmosphère n'est pas difiérente de celle des fenilles.

La coüncidence du développement des étamines avec la plus grande intensité d'action des parties colorées les fleurs, nous a porté à penser que l'usage de celles-ci était de fournir la nourriture aux premières; el comme les ovaires commencent en mème tcmps ì se développer, nous arons présumé qu'ils recevaient des mêmes organes une portion de leur aliment. Ce dernier eflę est bien plus probable dans les fleurs femelles, et dans celles dont les lépismes persistent après la floraison. J'ai déjà dit que le lépisme persistant du Cobu'a scandens alimentait vraisemblablement les jeunes graines quand la fécondation était opérée. Mais cetre fonction devient presque évidente dans les Pomacćes,

(1) Cons. sur la nat. et les rap. etc. pag. 49 ,

(2) Ouv. cité, pag. 15. 
et ce qui se passe lors du développement du fruit de ces plantes est assez remarquable pour que nous en fassions un rapide exposé.

On confond sous le nom de sarcocarpe la portion pulpeuse et mangeable des poires, des pommes, ete., avec celle qui entonre les abricots, les cerises, les pêches, ete. ; cependant elles ont une origgine tout-à-fait différente. La pulpe des Amygdalées (abricots, cerises, etc.) est le résultat du développement d’un vrai sarcocarpe, portion moyeme du péricarpe, tandis que dans les Pomacćes, c'est l'accroissement du lépisme intérieur (disque pérygine ) persistant, qui produit ce qu'on a très-improprement appelé leur sarcocarpe.

Dans la lleur de l'amandier, etc., dont nous arons parlé ailleurs (1), une lame glanduleuse qui se termine au haut du unbe du calice, donne naissance anx étamines et anx pétales, et forme avec eux, arons-nons dit, l'androcée extérieure ( 2 ); celle-ci est recouverte à sa base par une antre lame glandulense plus colorée, que nous avons regardée comme l'androcée intérieure rudimentaire (5). Pendant que les pétales, les étamines, et les lépismes glanduleux remplissent leurs fonctions, l'ovelle unique libre, qui oceupe le centre de cetce flew, prend quelque aceroissement. L'acte de la fécondation étant accompli, le calice ainsi que les étamines et les lépismes se dessìchent et tombent; l'ovelle seul persiste en en développant produit le sarcocarpe épais que nous mangeons lorsqu'il est succulent.

Ici le lépisme glanduleux meurt après avoir contribué à la nutrition des ćtamines et de l'ovaire; mais dans les Pomacées les choses se passent antrement; leur calice est recouvert, comme

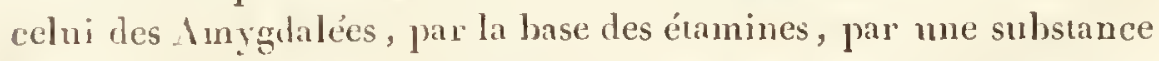
glandulcuse qui les accompagne, et par un lépisme glandulenx

(1) Cons, sur la nat. et les rap. etc. pag. 76.

(2) Ouv. cité, pl. 2. fig. 3. c. 6. b.

(3) Ouv. cité, fig. 4.6. co - Fleur d'un pêcler. Duham. Phys, des Arbres. t. 1. liv. 3. pl. g. fig. 2i; c. c. 


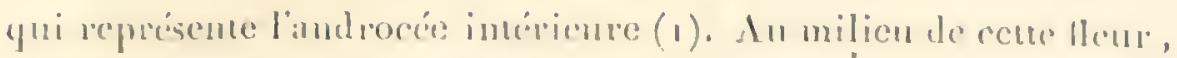
on trume: an lien d'un orelle mique, ring orelles distincts, lihres

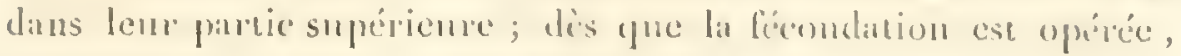

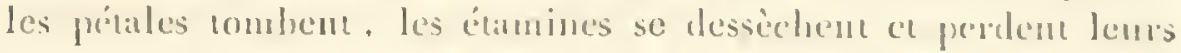

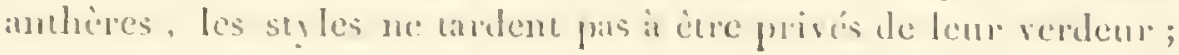
mats le calice et aser lui les lépismes persistent ed prennent de lanceroissement. Bientir ils emeloppent si complitement et si curoitement les ovelles pue ceux-ci, ensevelis pour ainsi dive sous cette nouvelle probi, contactent avee elle une athirence intime dins tonte leur étendue: alors les ovelles, qui étitient distincts dans la lleur, ne sont plus en apparence que les loges d'un fruit clarmu dont le calice en le léprisme incéreur développrís, forment le péricarpe. Il est aisé de sen convancre, soit en coupant une poire ou une pomme en travers el longitulinalement, soit en jetane les yeux sur les figures de ces coupes qui ont été publiéces par Grew et par Duhanel (2). On y rerra distinctement le vai fruit au centre de la substance charnue forméc par le développement du lepisme. Comment se sont oprirés les changemens qui ont eu licu dans l'état de ces partics? C"est Dulamel rui vat nous l'apprendre, et les filts quil a ohservés s'accordent de tout point avec la théorie que nous arons admise.

Après que les étamines ont rempli leurs fonctions, la portion glanduleuse de l'androcée extérienre qui déborde le tulse du calice, clange graducllement d'aspect, s'endurcit et forme plus tard dans les poires le corps granuleux yue Duhamel nomue partie exhérieure de lu roche (j), corps granuleux 'qui л’csu qu'un

(1) Malpigli, Opera omnia. Anat. plant. Tub. 44. Pyrus. fig. 2jı. Malus. fig. 252 .

(2) Grew. Anat. tab, 67. Poirt coupée transversalement. fig. 1. - Poire coupéc longitudinalement. fig. 2. - Coin coupé longitudinalement. fig. 5. - Dulamel. Phys. des arbres. liv. 3. Poire coupée transversalement. $1 \%$. 8. fig. 237. - Poire coupée longitudinalement. $\%$. 9. fig. 238.

(3) Duliamel, l. c. liv. 3, p. $24 j, p l$, 8. fig. $226, p, 25 z$. 
amas de tissu cellulare durci (1). Mais cet organe glandulenx n'est, arons-uous dit, que la sommité du lépisme extérieur qui tapisse tont le tube du calice; ì la place de ce hépisme, nous retrourons dans le fruit ce que Duhamel a appelé l'enseloppe pierreuse (2), éest-ì-dire une conche de issu cellulaire derenu calleux: quelquefois mème les bases des étamines prennent la même consistance.

Pendant la floraison, le lépisme intérieur prend quelque accroissement; il forme au-dessous des sommités du calice, le gonllement qui fait dire que les fruits sont noués (j). A cette époque, ces fruits restent stationnaires jusqu’à ce que les pepius soiemt parvenus à leur grosseur naturelle (4); la substance blanclıe, compacte et le tissu serré quioffrait le lépisme intérjeur, sont convertis graduellement en une matière dure et graveleuse qui ne fournit plus d'alimens aux orules; mais quand les pepins ont acquis presque tout leur déreloppement, le lépisme alors completement endurci, sans communication directe avec l'atmosplière, est nonrri par l'action de la surfare extérieure du calice; celle-ci décompose pendant le jour le gaz carbonique qu'elleabsorbe et celui qui lui est apporté par la végétation; elle s'empare de son carbone, pour le convertir pendant la nuit en matière nutritive. Ce licquide alimentaire se porte avec abondance vers les cellules qui entourent le tissu endurci du lépisme, et de cette manière se forme la clair des fruits des Pomacées, souvent au détriinent de la graine (5). On sait, en effet, que généralement la chair des poires reste dure et granulense lorsque les pepins sont wèsbien nouris, comme on l'observe dans les poires saurages; et au contraire, lorsque le lépisme gorgé de sues nous présente une chair savoureuse, les graines sont moins parfaites on dis-

(1) Voyez Grew. $t a b .67 \cdot$ fig. 4 .

(2) Duhamel. ouv, c. liv, 3, p. 243. pl, \&. fig. 224.

(3) Duh. ouv, c. liv. 3. pag. 242 .

(4) Duh. liv. 3. pag. 256.

(5) Duh, p. 256 et 257 . 
paraissent, ainsi quion he voit, palresemple, daus le Bon-Chréticn d'.luch, oir elles sont prestgue unters avorties.

Il suit, ee me sumble, de ec yue je viens d'erproser, que le depisme incirienr persistant des Pomacées fommit de lablinent anx

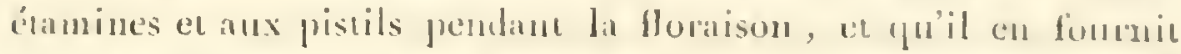

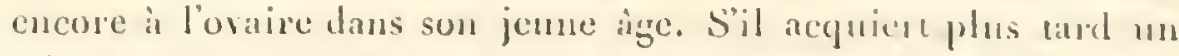
très-grand développement, c’est pau une surabondance de nutrition an moins superflue pour le fruit, quand elle ne lui est pas nuisible, comme lorsquelle coüncile arec l'avortement des gratines : aussi cet accroissement extraordinate n'est-il le plus sourent quiur résultar de la culure.

S. II. De l'excrément des lépismes. Après avoir énuméré les fatits qui servent de base à mon opinion sur les fonctions untritives des organes glamblenx de la fleur, il me paraí convenable de jeter un coup-d'oeil sur leur excrémenl sueré, si connu sous les noms de nectar et de miel. Cete substance n'a pas été soignensement examinée, prise imméliatement sur les lleurs; mais on comait miens celle que nous enlerons à quelques-ums des hymenoptères qui la rassemblent. Les faits connus doivent nous faire admettre comme une chose très-probable, que le miel, matière excrémentiticlle de's léprismes glandulenx ou nectaires, participe des propriétés géncirales de la plante qui le produit.

Quelques espèces vraisemblablement huinent toujours sur les mênes plantes, et leur miel a un caractère proriculier; cel est celui d'une couleur verte que donne i l'ile de France et ì Hadagrascar l'Apis unicolor; mais une mime espree d'insecte peut produire des miels anssi différens que les lleurs où elle les recreille.

La densité, le goir, Jiı couleur, et l'arôme du uniel de l'spis mellifica varient beaucoup, selon les localités qui le produisent et selon l'épougue de l'amnée pendant laquelle il est récolté ; des différences de mème nature s'observent aussidluncannce ì une autre, d’après la série des plónomenes atmosplériques qui se sont succédés. J.e miel transparent et fluide de Malıon, du Mont-Mýmeute, du Mont-Ida, de Cuba. etc., sout, au rapport de Bosc, aussi 
supérieurs au miel blanc el compact de Narbonne, que ce demier est au-dessus du plus maurais des environs de Paris. La conleur blanche est regardće, chez nons, comme un indice de la bonté de coue substance, et il est, dans les îles Balćares, des micls noirs dont le goùt est, dit-on, délicienx. Tous les agronomes savent encore que la même ruche donne chaque mois des prodnits différens, et que chaque mois correspondant de deux années rien présente pas de semblable. Toutes ces différences ne sauraient avoir d’aures canses que la diversité des plantes sur lesquelles les abeilles butinent à chaque époque de l'annce, et les modifications que fait éprourer à l'excrétion dn lépisme l'action variable de l'atmosphère.

D'autres faits observés, paraissent appuyer plus directement cette opinion. Ies flenrs des orangers fournissent, dit-on, l'excellent miel de l'ile de Cuba, et le meilleur, dans notre Lurope, est celni que produisent les pays oì croissent abondamment les plantes aromatiques de la famille des Labićes. Mr. Biot, dans les ŝles Baléares, et MI. de Candolle, dans les Corbières près de Narbonne, ont constaté que c'était an romarin seul qu'était due la supériorité du miel de ces deux localités; et Olivier a observé que celui de la lante Provence dont la qualité est excellente, est récolté sur la liarande. On sait encore, d'après M. Allaire, que les fabricans de pain d'épices de Rheims paient plus cher le miel du printemps provenant du sanle marcean, et n'estiment pas celui d'automne formé au dépens du sarrazin, etc. (1).

Mais ce qui proure mienx encore, que le micl jouit des propriétés générales des plantes sur lesquelles il a été récolté, c'est qu’il exerce une action délćlire sur l'économie animale, lorsqu'il a été extrait des régétanx rénénenx (2).

(1) Dict. d'agricul. art. abeille, de Bosc, I. pag. GG.

(2) Je ne puis micux faire que de rapporter textuellement le résultat des rccherches faites sur ce sujet par M. Aug. de S.t.Hilaire. Voyez relation d'un empoisounement cansé par le miel de la guêpe lecheguana. Plantes les. plus remarquables du Brésil et du Paraguay. vol. I. 1825. 


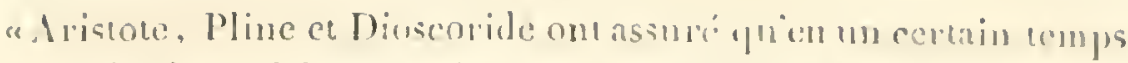

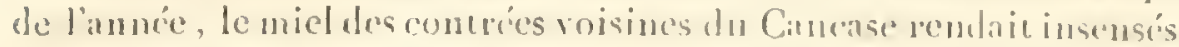

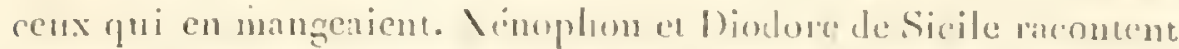

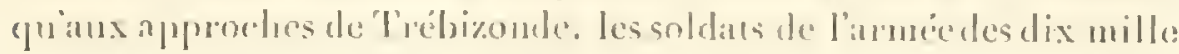
mangerent du micl qüils trouverent dins la campligne; quensuite ils éprouverent un délie de plusienrs jours, et pue les ans ressemblaient it des ivrognes, les antes i des furiens on ì des moribonds. Quelrues modernes ont confremé res récits, et ils ont reconnu que éütient les lleurs de l's Ealea pontica. et pent-

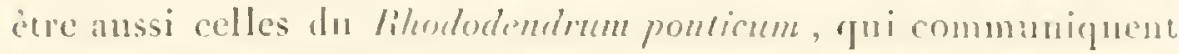

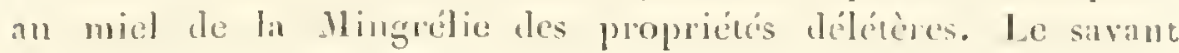
M. Tabillardière soupegonne que les compoisonnemens cansés jar le miel de l'Asic mineure pontraient cure dus an Memispermum cocculus. An rapport de l'illustre l'itton de Tournefort, le P'. Lambert dit que le miel recueilli sur un revtain arbe de la Colchide occasionne des romissemens. Tommefort lni-même (roy". II, pag. 228) assure quine tradition constance ćablie parmi les habitans de la Mer Noire leur fait considérer comme dingereux le miel sucé par les abeilles sur les fleurs de l'dzaler ponticu. Enfin un royagen plus moderne, Guldenstadt, le compagnon de Pallas, a vu lui-méne le mich recueilli sur l'dzalea; il l'a trouve d'un brun noir, d'un gout amer, et dans plusienrs cndroits de ses onvages il dit que ce miel cause des élourdissemens et 'qu'il rend insensé (Reis. I. 1. 275. 2S1. 297.)."

"L'Asie mincure n'est pas la senle contrée ou lon ait trouvé du miel d'une qualité dangereuse. Voici comment s'exprime fonlox Barro dans son voyge au brésil, traduit par Loreau en rfíj: "Les plus gaillards des Tapuies furent chercher du micl samvage " et des fruits, desquels il lirent un brenvage qu'on nomme de " la grappe, duquel quiconque huvait vomissait anssitot. " Dans lile de Marignon, l'abeille Mumbuer va quelequefois, suivant Pison (Bras. 56), se reposer sur la fleur de l'arbre appelé T'apuraïb, et alors son micl, ondinairement déliciens, devient entièrement amer. Azzara est bien plus précis encore; car il s'exprime 
comme il suit dans son $T^{\top}$ orage an Paragnay: "Le miel d'une " abeille appelé C'abatatu dome un violent mal de tète, et cause " une irresse an moins aussi forte que celle que produit l'en" de-vie. Celui d’une autre espèce occasionne des convulsions " et les plus riolentes douleurs, qui se terminent au bout de " trente henres sans produire ancune suite fâcheuse. Les gens " de la campagne connaisseut bien ces deux espèces, et ils n'en "mangent pas le miel, quoique le goû en soit aussi bon que "celui des aures, et que leur couleur soit la méme."

"Le miel de la Pensylranie, de la Caroline méridionale, de la Georgie, des deux Florides, lorsqu'il a ćté recueilli sur les Kalmia angustifolia, latifolia, hirsnta, et sur l'Andromeda mariana, occasionne souvent, selon Snith Barton (in N ichols. journ. vol. T. p. 159. 165 (r)), des rertiges auxquels succède un délire dont le caractère varie suivant les individus. "Les personnes " empoisonnées, ajoute le même auteur, éprouvent des maux " d'estomac, des convulsions, des romissemens, et quelquefois "ces accidens sont suivis de la mort."

"Ce n'est pas seulement en Asie et en Amérique que l'on a eu des exemples deenpoisonnemens causés par certains micls. Seringe raconte que deux pâtres suisses, qui araient mangé du miel sucé sur les deonitum napellus et becoctonum, éprouvèrent de violentes convulsions, furent atteints d'm lorrible délire, et que l'un des deux, qui ne prut romir, mourut en rendane par la bouche une écume teinte de sang (Nonographie du genre Aconitum in Mius. Helv. vol. I. p. 12S.)"

"Tant d'autorités rémies n’étaient pas connues sans donte à cenx qui de nos jonrs encore ont traité de fahuleux les récits de l'historien des dix mille. "Mais si ces récits avaient besoin d'une nourelle confirmation, on la trouverait dans le fait curieux que nous a fait connaître le sarant naturaliste à qui nous venons

- (1) L'opuscule de Smith Barton se trouve cité dans le Dictionnaire de Klaproth ( $r .111$. p. 147 ), mais de la manière la plus erronée. 


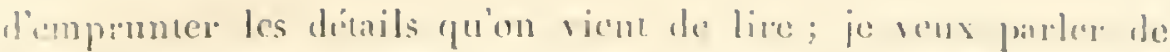

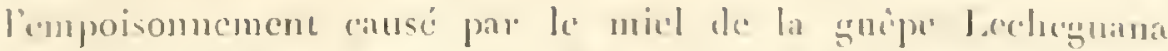
('Polistes Lecheguane), dom 11. A. de S.'-llilaire a failli cue la viclime.

Apres aroir parecomen les campagnes rianes du lido de la Plata, ce célibe natualiste avilit cotoye les hords moins habitrs do

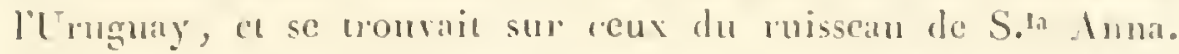
Dans ce lien désere qui n'est peuplé que par une mulciude de jighalls et d'immenses trompeanx de jumens sauvages, de cerfs

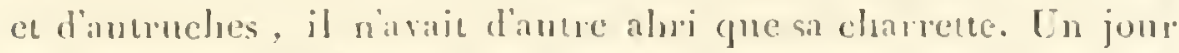
arcompagne de dens de ses gens, il parenurut les ampagnes curiromanes eu les bords de l'l ruguay. An hout de quelpues heures, rameni's tons wois par la firm sur les bords du ruisson, ils la satisfurent arec lenrs alimens ordinares, de la farine de manhioe et de la clanir de vache rôtie on bonillie. Les denx compagnons de M. de S.I- Hilaire araient aperegu la veille un gurpier qui était suspendu ì environ m pried de terre à l'une des branches d'un petic abrissean. Après leur déjonner, ils allerent dênure ee gnépier, et ils en tirèren le miel. "Nons. en gonthmes tous les trois, njonte notre voyagenr dont je vais transerire litéralement les paroles, pons que le lecteur ne perdent rien de l'intérè que présente si relation; " je fuscelui qui en mangeni le plus, ex je ne puis gnire évaluer ce que jen pris quà em iron denx cuilleres. de tronvin ce miel d'me doncen agréable et absolumesu exempt de ce goût pharmaceutique qu'a si somren celui de nos abeilles."

"Cependant après en aroir mangé, jéprourai une douleur. d'estomac plus incommode que vive; je me conchai sous ma charuete et je mendormis. Pendant mon sommeil, Jes objets qui me sont les plus chers se présentèrent à mon imagination, et je méveillai profondŕment atcendri. Je me levai, mais je me sentis d'une telle faiblesse yu'il me fru impossible de faire plus de cinquante pas; je retourmi sous ma charreue; je métendis sur le gazon, et me sentis presque aussitôt le visage baigné de 
larmes que jattribuai ì un attendrissement causé par le songe que je renais d'aroir. Rougissant de ma faiblesse, je me mis ì sourire; mais malģré moi, ce rire se prolongea el derint conrulsif. Cependant j'eus encore la force de donner quelques ondres, et, dans l'intervalle, arriva mon chasseur, l'un des deux Brésiliens qui avaient partagé avec moi le miel don je commençais ì sentir les funcstes elfets ".

"Jozé Mariano, c'est ninsi qu'il s'appelait, s’approcha de moi, et me dit d'un air gai, mais pourtant un pen ćgaré, que depuis nne demi-lıeure il errait dans la campagne sans savoir où il allait. Il s'assit sous ma charreue, et il mengagea ì prendre place ì côté de lui. J'eus beaucoup de peine à me trainer jusque-lì, et, me sentant d'une faiblesse extrême, j’ppruyai ma tête sur son épanle."

"Ce fut alors que commença pour moi l'agonie la plus cruelle. Un nuage épais olsscurcit mes yeux, et je ne distinguai plus que les uraits de mes gens et l'azur du ciel traversé par quelques rapeurs légères. Je ne ressentais point de grandes douleurs, mais jétais tombé dans le dernier affaiblissement. Le vinaigre concentré que mes gens me faisaient respirer, et dont ils me frottaient le visage et les tempes, me ranimait à peine, et jéprouvais toutes les angoisses de la mort. Cependant j’ai parfaitement conservé la mémoire de tont ce que jai dit et entendu dans ces momens douloureux, et le récit que m’en a fait depuis un jeune Français qui maccompagnait alors, s'est trouvé parfaitement d'accord avec mes souvenirs. Un combat assez violent se passa dans mon âme, mais il ne dura que quelques instans; je triomplaai de mes faiblesses et je me résignai à mourir. Ce qui maffectait le plus, c'était le sort de mon Indien Botocude que j’avais tiré de ses forêts, et que je croyais deroir être, après ma mort, condanné à l'csclavage. Je conjurai ceux qui m'entourajent d'avoir" pitié de son inexpérience, et de répéter à mes amis, lorsqu'ils les reverraient, que mes derniers roux avaient été pour cet infortuné jenne homme. J'éprouvais un désir ardent de parler 


\section{5}

dans ma langne an l'mm:as qui me prodigualit ses wims, mais

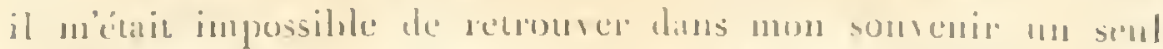

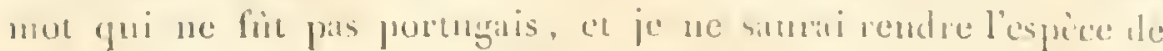

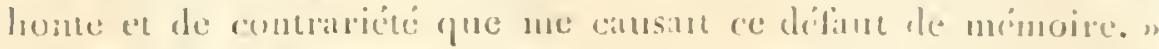

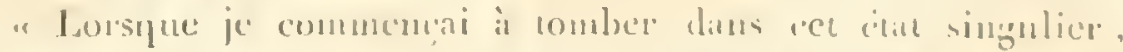

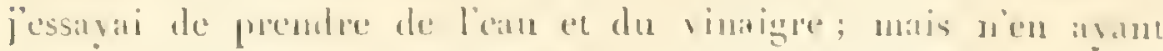

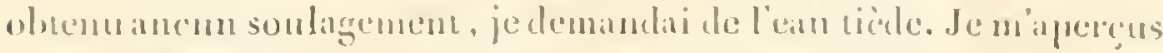

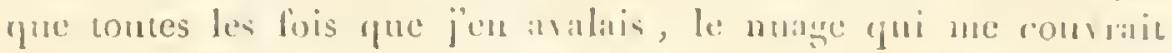

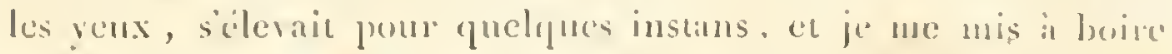
de lean tiede à longas taits et prespue sans intermplion. Sans resse je demandais mu vomilif an mon jenne franeacis mais comme il ćtaic trouble par tont de qui se passaic autonr de lui, il lni lin impossible dien tronver mo. Il cherchait dans la clanrete; jétais assis dessous, "e par conséquent je ne powvais l'apereervir: repentane il me semblait fu’il atait sous nes yeux, et je lui reprochais sa lentem. Cesi la seule crreur ou je sois tombé pentant cette cruelle agonie."

"Sur ces entuefaites. le chasseur se lera sans que je mien apercusse; mais bientotmes orcilles furemt fraplées des cris affreux quil poussajt. Dans cet instant je me trouvai un peu micux,

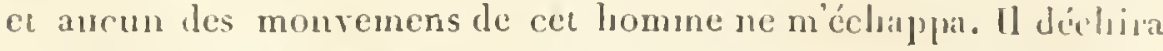
ses vìtemens aree fureur, Ies jeta loin de lui, prit un fusil et le fit pratir. On Lui arracha son arme des mains, et alors il se mit à courir dans la campragne, appelant lit Vierge à son secours, et criant avec force que tout était en fen autour de lui, fuion nous abandonnait tous les leux, et quon allait laisser bribles nus malles et la charette. Un pion Guarani fui faisait partic de ma suite; atyut essayé inutilement de retenir cet homme, fut saisi de frayeur et prit la fuite."

"Jusqu'alors je n’avais cessé de receroir des soins du solılu qui arait partagé arec moi et mon classeur, le miel qui nous arait été si funeste; mais lni-mène avait commencé par due lort malade; cependant, comme il arait romi trés-promptement et qu'il était d'un tempérament robuste, il avait bientòt repris des 
forces: il s'en fant pourtant qüil fût entièrement rétabli. J'ai su defuis que, pendant guiil me soignait, sa fignre était efrrayante et d'une pâleur extrême. "Je vais, dit-il tout-ì-coup, donner " avis de ce qui se passe ì la garde du Guaray. "Il monte "艹 cheral et se mit à galoper dans la eampagne; mais bientôt le jenne français le vir tomber; il se releva, galoja une seconde fois, tomba encore, et, quelques heures après, mes gens le trouvèrent profondément endormi dans l'endroit où il s'éaic laissé tomber."

"Alors je me trouvai senl et presque monrant encore aree un homme furieux, mon indien Botocude qui n'étaic qu'un enfant et le jeune Français, que tant d'événemens extraordinaires avaient pour ainsi dire privé de la raison.

"Cependant l'ean chande dont javais bu une quantité prodigieuse finit par produire l'ellet que j’en arais espéré, et je romis, arec beancoup de lipuide, une partic des alimens eu du miel que javais pris le matin. Je commencai alors à me sentir sonlagé; un engourdissement assez pénible que jépronvai dans les doights fut de conrte durée; je distingmai ma ellarrette, les pâturages et les ardores voisins, le nuage qui auparavant avait caché ces oljets à mes yenx ne m’en dérobajt plus que la partie supérieure, el si quelquefois il s’abaissait encore, ce n'étrit que pour quelques instans. Qnoi qu'il en soit, l'état de Jozé Mariano continuait à me donner de vives incuiétudes, et j'ćtais également tomrmenté par la crainte de ne jamais recourrer moimême l'entier usage de mes forces et de mes facultés intellectuelles: un second romissemen commenȩa is dissijer ces craintes, et me procura un nunvean sonlagement; jeus moins de peine encore à distingner les objets dont jétais entonré ; je commcrnçi à parler à mon gré le portugais et ma langue matcrnelle: mes idées devinrent plus suivies, et j’indiquai charement an jenne Français où il pournit trouver m romitif. Quand it me l'ent apporté, je le divisai en trois portions, et je romis, avee des torrens d'eau, le reste des alimens que javais pris le matin. 


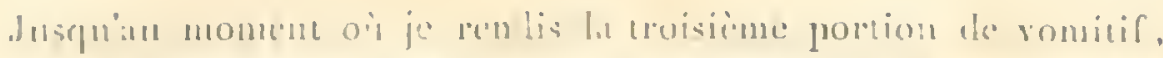

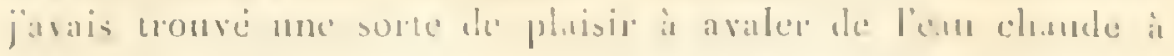
Jung traits; alors alle commentä

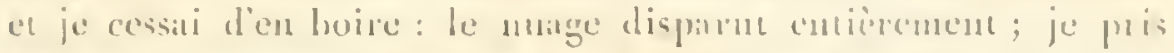

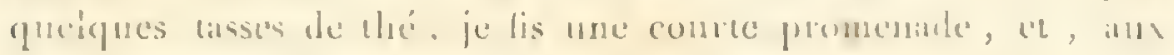

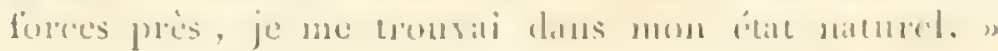

"A peu pres dans le méme moment, la rason revintom-

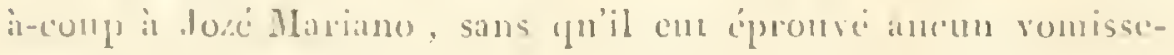
ment.

"Il pourait sue dis lecures du matin lorsque nous gontimes inus les lruis lo miel qui nous fit tant de mal, et le solvil se

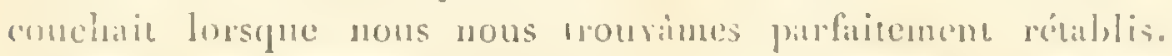
Labsenec momentanée du firangais en de l’indien botocule les anat préservés de manger du miel avec nous. Le soldat en avirit présenté a pion Guarani mas celui-ci qui en commaissait la qualité délétere avait refusé d’en preneles le brasilien avait ri de sa crante, il n’avail pas mème cru deroir mon firire part. "

"Un peu arant d'arriver au licu oì nous nous arretames le juu" yui suivit notre empoisonnement, je fus appele par le soldiat. yni me montra un guêpier semblable il celui de la reille; il arait la mime forme, les mèmes dimensions, la mème consistance: il était égrilement suspendu i l'nue des branelues les plus basses d'un petic arbrissean, et mon pion Guarani, ainsi que le nourent guide, ma ante pion et plusienrs Indiennes qu le gonide arait amences arec lui, reconnment ee guipier pun appartenir, comme celui de la reille, it l'espéce connue dins le prys snus le nom de rechegreana: mon soldat s'emparil du guipicr el i! m'apporta quelques-unes des monclies, ainsi que des fragnens de lem demenre. Les gatenux que jai remis, arec le gunpier, an cabinet du lioi o raient pareils a cenx yue jarais eu entre les mains le jour précident; le miel dont ils firant remplis avait la couleur rougétire de celui de la veille, 't il étaic également ùis-liquide. " 
"On se représentera sans peine létonnement et lc cluggrin que j'épronvai, Jorsque le soldat me dit que mon indien Botocnde, ģui avait été témoin de notse empoisonnement, et le pion du gutide araient mangé de ce même miel, et que leur exemple avait entrainé mon pion Guarani ; je ne pus m'empècher d'accabler ces hommes de tontes les marques de l'indignation et du mépris. Ce miel ne me fera pas de nal, me répondit froidement le Botocude, il est si doux! paroles qui caractérisent parfaitentent les Indiens, tout entiers au présent et sansinquiétude sur l'arenil". ”

"Mattendant à roir les scènes de la veille se renoureler, je préparai des romitifs; jenroyai mes gens se coucher, ef je me mis a traviller dans ma charrette. A minnit, tont étai antomr de moi dans la tanquillité la plus profonde; jéveillai le Botocude; il m'assura qu'il se portait à merveille, et la muit achera de se passes sans accident."

"Aussitòt que je fus sorti des déserts où j"étais alors et que jentrai dans lit province des Missions, jinterrogeai heaucoup de gens sur le miel des lecheguana. Tous, portugais, guaranis, espagnols, s'accordèrent à me dirc que l'on distingnait dans le pays deux espéces de lechcgnana ; l'une gui donne le miel blanc (lecheguana de mel branco), et l'autre qui produit du miel rongêture (lecheguana de mel vermelho); ils ajoutèrent que le miel de la première espèce ne faisajt jamais dı mal; que celui de la seconcle, la senle que je connaisse, n'en causait pas tonjours; mais que quand il incommodait, il occasionait une sorte d'ivresse ou de délire, don on ne se délivrait que par des vomissemens, et qui allair quelyuefois jusqu” donner la mort."

"On m’assura que l'on commaissait parfaitement la plante sur laquelle la guêpe lecheguana va souvent succr un miel empoisonné; mais on ne me la montra poin et je me tronve mallieureusement réduit à former des conjectures."

Il résulte d'une dissertation intéressante de M. A. de S.t-Hilaire sur les plantes vénéneuses du Brésil méridional, que très-probablement le Paulinia australis (A. de S. IIT.) a fourni le miel 


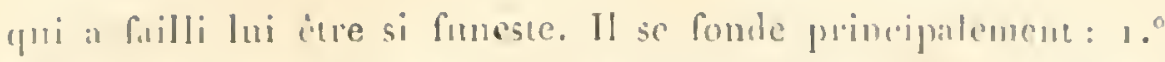

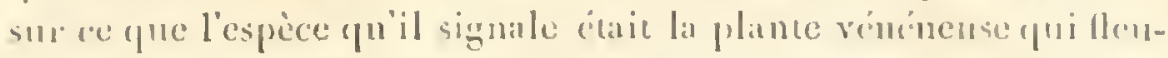

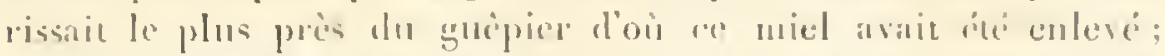

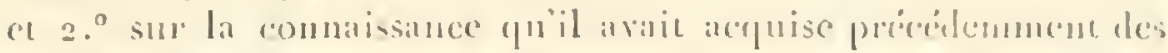

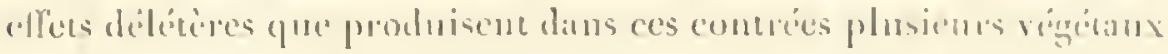
we lat méme fiunille. Quoi qu'il en soir, la relition que mons

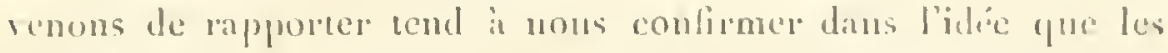
miels recucillis par les memes hymenoptiones ont des quilites dillérentes selon les plantes qui les ont fonmis, ex cqu'ils partticipent de's propriches gurnerintes de ces plantes.

\section{RESLME.}

1. Les organes flomux colorés et glandulenx paraissent renfermer, eomme les grames, tes matérianx qui doivent foumir laliment vigrial.

II. Ises conditions de lenr díveloppement sont scmblables a colles qui alecompagnent la germintion des granes.

IIt. Comme ces dernives durant la germinaton, les organes florax' et glanduleux pendant leur drveloppenent, dímisent du gaz oxigìne de linir, et le remplacent par lu ga\% acide cal's honique.

IV. Dans la floraison comme daus la germination il y a production de claleur, an moins diuns quelques cas.

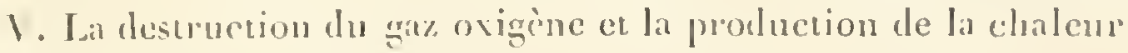
far les organes de la flen parait étre en raison directe de lat matière glandulense qu’ils renferment, et en raison inverse de la mative verte quils peuvent anssi posscider.

VT. Lorspüils sone pourvus de matière verte, ils ont des fonctions entiènement semblables ì celles dies fenilles; et romme on wouve dans les fleurs tous les degrés intermediaires enue lorgane le plus vert de la cunsistance la mojus glandulense, et lorgane coloré qui es le plus glanduleux, il son suit quidles doirent ofrir aussi tous les degrés intermédinires cntre la double 
fonction de la feuille la plus prafaite et la fonction unigne de l'organe glanduleux le plus coloré.

VII. Lorsque les organes fïuraux glanúuleux ont été en contact arec le graz oxigène, un liquide sncré suinte de plusieurs de leurs parties, et parait formé aux dépens de la fécule qu’ils renferment, ainsi que cela se passe dans la germination.

Vilf. Le liquide sucré qui s'échappe des nertaires el qui s'accumule dans les cavités des fleurs, paraî̀ une sorte d'excrément de matic̀res surabondantes.

IX. Si les mêmes plénomènes s'obserrent pendant la germination et durant la flomison, n'est-il pas probable que ces phénomènes ont des résultats analogues; or, le liquide sucré qui se forme pendant la germination aus dépens de la fécule des graines sert à la nourriture de la gemmule; celui qui se forme de la même manière lans les parties colorées de la llcur, me doit-il pas fournir de l'aliment aux organes sexuels?

$\mathrm{X}$. Cente hypothèse deviendra plas probable, si l'on considère que la destruction du gaz axigène, la production de la chaleur et l'excrétion du nectar par les organes floranx, acquièrent leur maximum d'intensité it l'ópoque de la plus grande activité des fonctions sexuelles.

X1. La ligueur des nectirires, connue sous les noms de nectar ou de miel, ofrre des différences selon les espèces de plantes qui la produisent, et surtont elle participe de leurs propriétés générales.

On me reprochera pent-être de m’être borné à la création d'une hypolhèse sans l'appuyer par des observations el des expériences nouvelles, qui auraient du moins leur utilité, lors même qu'il serait prouvé que je me suis égaré dans mes raisomnemens. A cela je pourrais répondre qu'une ly pothèse qui s'accorde aree ales faits déji connus, a toujours quelque utilité ; car si elle esı 


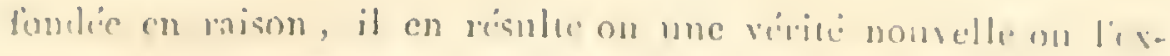

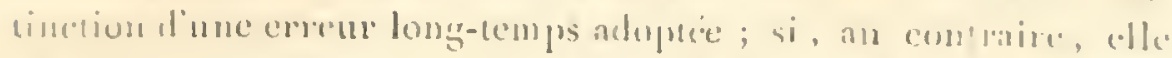

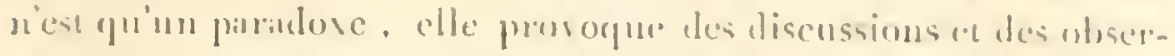

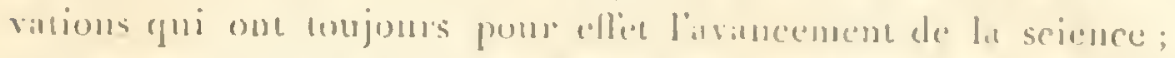

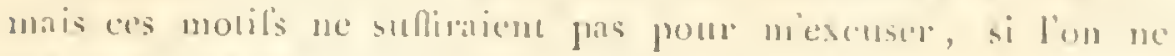

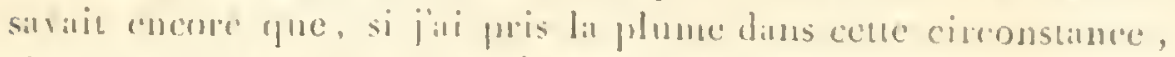
cest pour mareguiter d'un ileroir (1).

\section{FIX (2).}

(1) Ce petil écrit a été présenté, comme second trihut acalémique, it la facule des scienees de Montpellier, pour obtenir le grade de doctenr-esscierces.

(2) Cille dissertation venait ì peine d’ètre imprimbe, Inreque jai eu connaissance de plusicurs ouvages ou je trouve la matiere de quelques addilions i) l'histoire sommajre des usages des parties colorkes des lleurs (voje\% page 8 ).

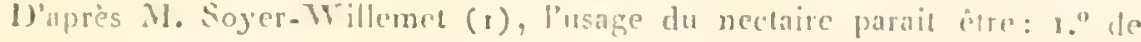
fournir au stigmate un suc capable, par sil viscosite, d'y faje adhéver le pollen, "t, par son humidité, den operer lis rupture (celte opinion est anssi celle? de M. Jose (s)); $2 .^{\circ}$ de lubuifor le canal qui conduil la liquenr fécondante sur les orules, de faciliter sou ditoulement, ou des sopposer à son absorptiou pendant le trajel; $50^{\circ}$ enfun le nectar doit itre anx osules ce que la liqueur le l'amnios est au fortus, un liquide copable d'aider à leur développement el de louruil a leur premiere nomriture.

M. Soyer-Willemci a répié l'expérience de Poniérlera (roy. pag.li), sur l'Aquilegia volgaris el l'Alconimum napellus; il a oblenu les mines résulents que le botaniste italien. Lorsqu’il a rulevé, avant la fécondation, les ucctaires de ces plautes (pétales des modernes), les graines on avorté.

En jetant un coup-d'ocil sur les rapports des points nectariferes arec les pluénoménes de la végélation, M. Desvaus (3) rapporle quelques experiches de M. Perroleau de Poitiers, sur le sujet qui nous occupe (́f ). Au mojen

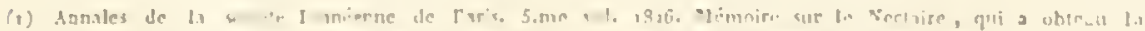

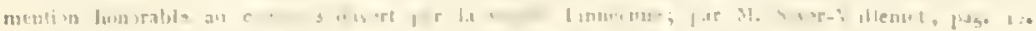

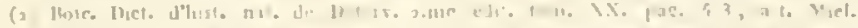

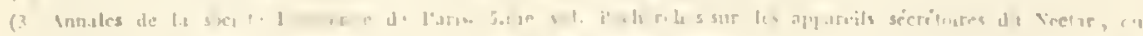

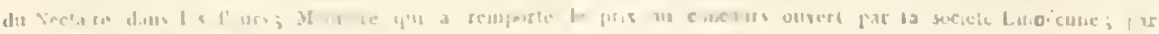

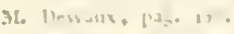

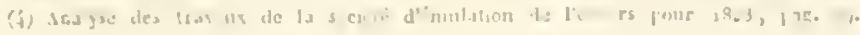




\section{0}

C'un iube de verre, ce médecin enleva le nectar de la frittllaire impériale; flle fut stérile. Il crut pouroir en conclure que les ovaires ne se développaient point dans les fleurs que l'on privait de leur nectar. M. Dessaux a répété l'expérience de M. Perrotteau sur la fritillaire impériale et sur plusieurs autres plantes. Une partie des fleurs qu'il avait privées de leur nectar, n'ont pas cessé de domner des fruits. Ce botaniste distingué a excisé l'éperon nectarilère de plusieurs Orchis, et souvent les ovaires ont continué de se développer. Lorsqu'il a retranclié les pétales nectarifères du Nigella damascena, la plante a porté des fruits comme à l'ordinaire, d'où M. Desraux a conclu que le nectar ne concourait en rien au développenent de l'ovaire. Dans toutes ees expériences, l'époque du retranchenent du nectaire n'a pas été notée, et elles sont trop vagues pour qu'on puisse en déduire aucun résultat positif. Dans sa piquante dissertation sur la métamorphose des plantes, Goethe, qui connaissait très-bien l'analogie des nectaires avec les étamines et les pétales, présume que le suc mielleux des fleurs est la matière fécondante imparfaite et imparfaitement déterminée (1).

(r) Issai sur la métamorplose des plantes, par 3.-Wh de Goelbe; traduit de l'allemana sur l'édilion críginale de Gothu $(1-90)$, pur M. Fréderic de Gingus-Lassiraz, pag. 4io 









7.

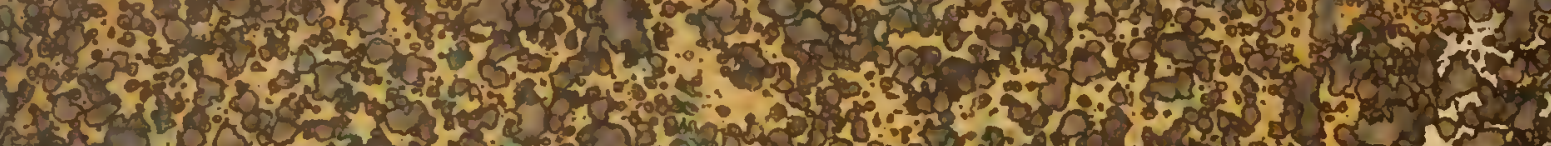

$x+7 x^{2}$

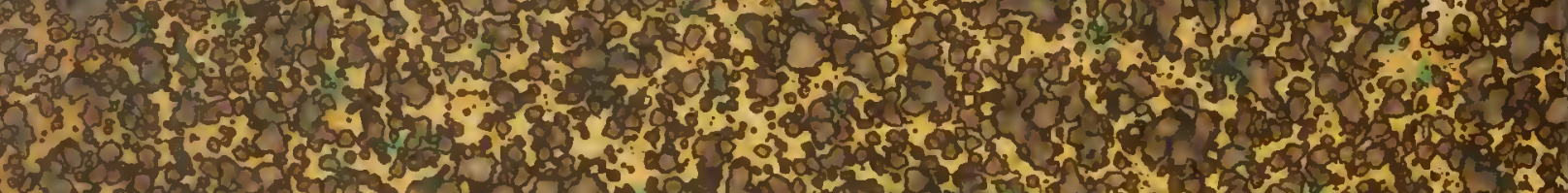

H. 3. 2.t. H.

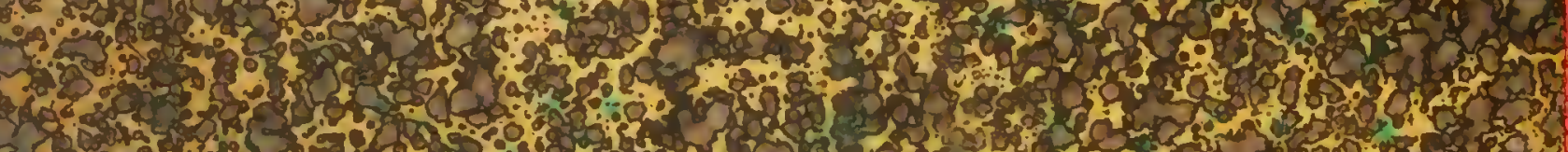
the. 7. - 57 . -

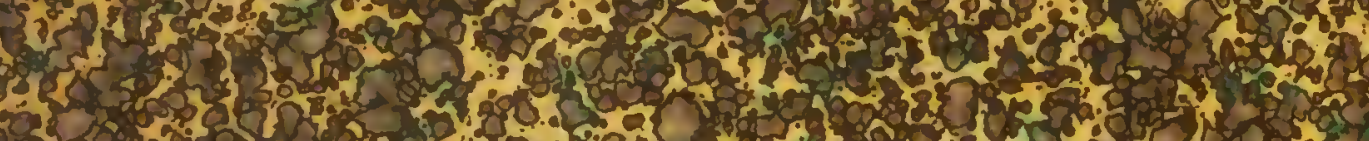

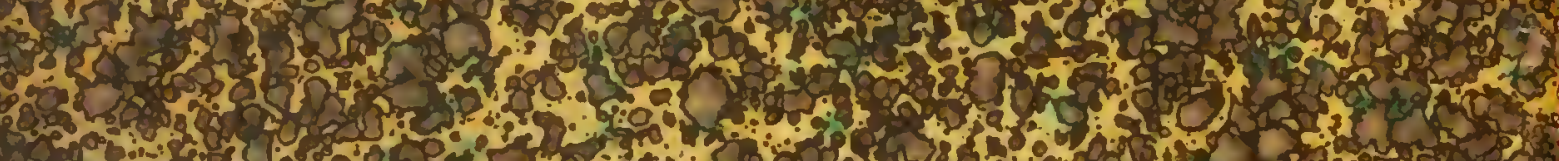

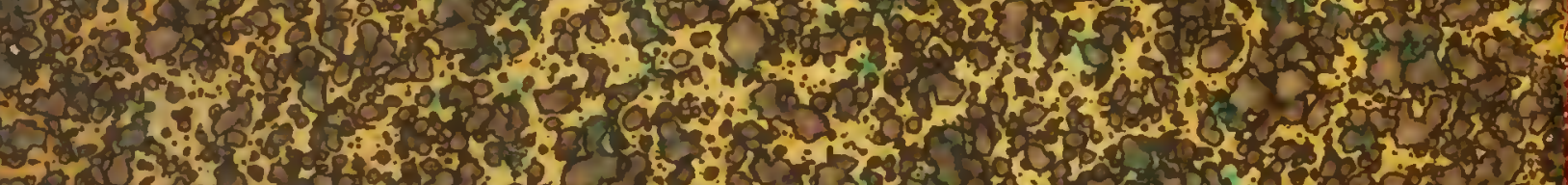

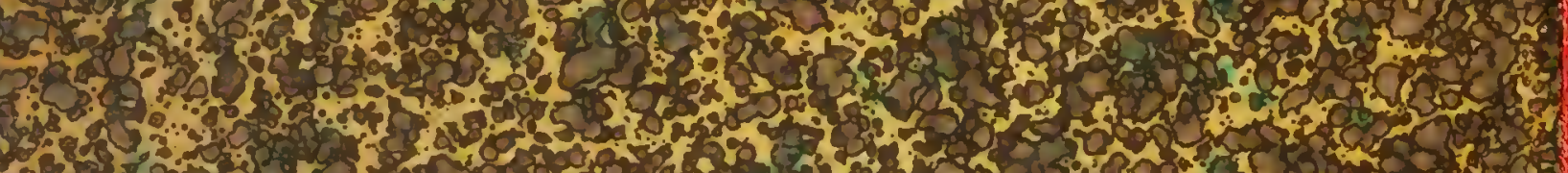

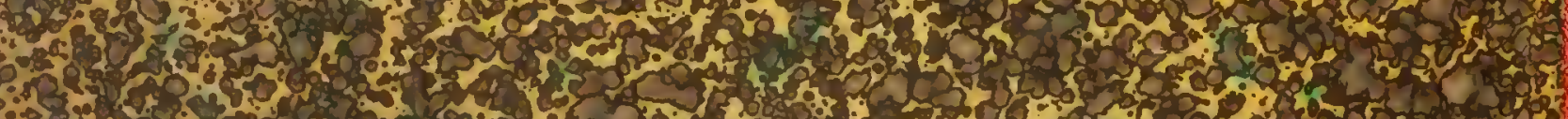

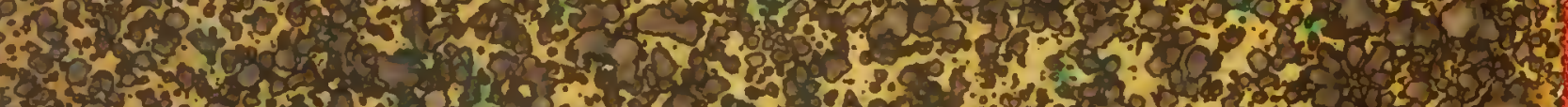

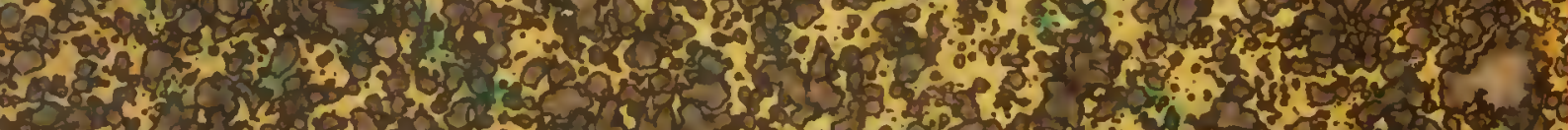

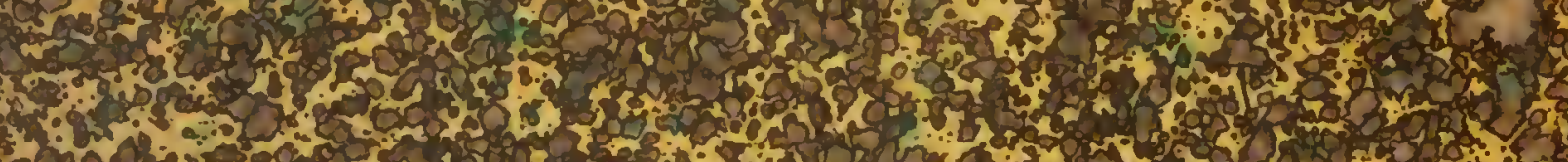

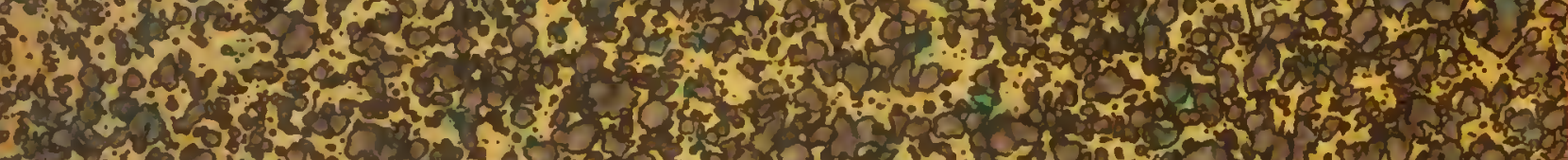

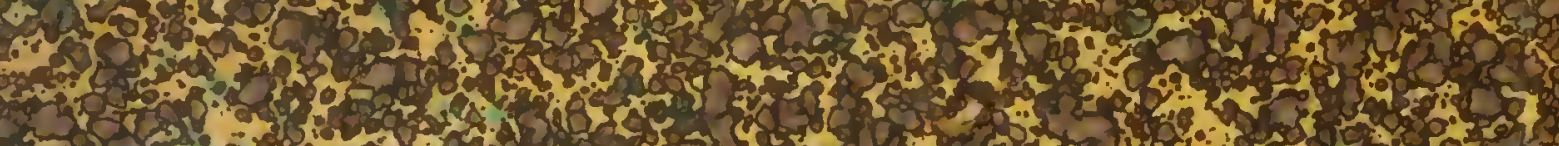

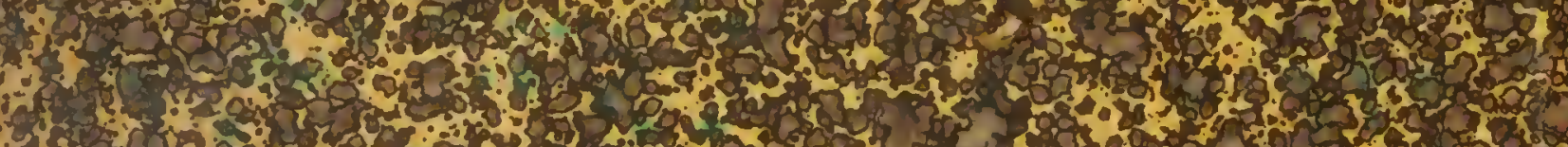

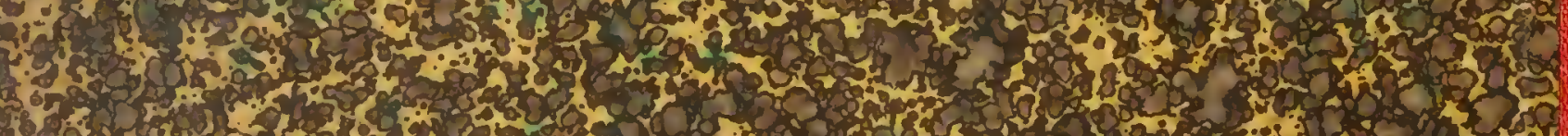

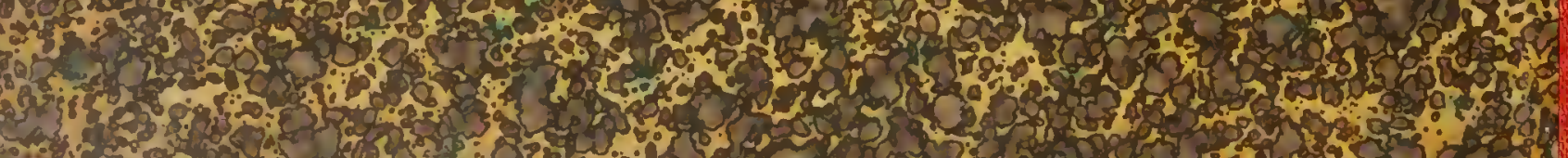

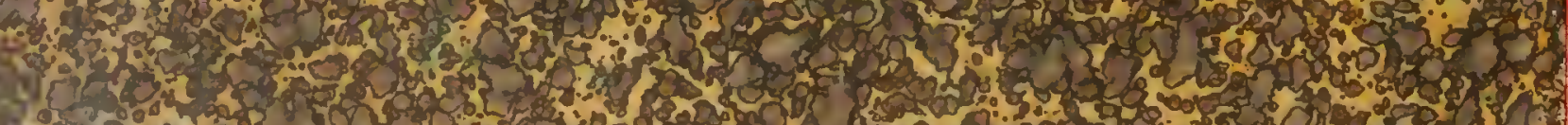

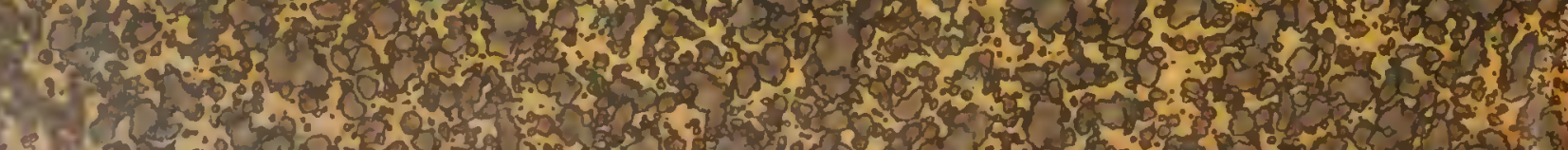

